\title{
Simulation study for the Stratospheric Inferred Winds (SIW) sub-millimeter limb sounder
}

\author{
Philippe Baron $^{1}$, Donal Murtagh ${ }^{2}$, Patrick Eriksson $^{2}$, Jana Mendrok $^{2}$, Satoshi Ochiai ${ }^{1}$, Kristell Pérot $^{2}$, \\ Hideo Sagawa ${ }^{3}$, and Makoto Suzuki ${ }^{4}$ \\ ${ }^{1}$ National Institute of Information and Communications Technology, 4-2-1 Nukui-kitamachi, Koganei, Tokyo 184-8795, Japan \\ ${ }^{2}$ Department of Space, Earth and Environment, Chalmers University of Technology, 41296 Gothenburg, Sweden \\ ${ }^{3}$ Division of Science, Kyoto Sangyo University, Kyoto, Japan \\ ${ }^{4}$ Japan Aerospace Exploration Agency, Tsukuba, 305-8505 Japan
}

Correspondence: Philippe Baron (baron@ @ict.go.jp)

Received: 12 March 2018 - Discussion started: 4 April 2018

Revised: 11 July 2018 - Accepted: 16 July 2018 - Published: 31 July 2018

\begin{abstract}
Stratospheric Inferred Winds (SIW) is a Swedish mini sub-millimeter limb sounder selected for the 2nd InnoSat platform, with launch planned for around 2022. It is intended to fill the altitude gap between 30 and $70 \mathrm{~km}$ in atmospheric wind measurements and also aims at pursuing the limb observations of temperature and key atmospheric constituents between 10 and $90 \mathrm{~km}$ when current satellite missions will probably come to an end. Line-of-sight winds are retrieved from the Doppler shift of molecular emission lines introduced by the wind field. Observations will be performed with two antennas pointing toward the limb in perpendicular directions in order to reconstruct the 2-D horizontal wind vector. Each antenna has a vertical field of view (FOV) of $5 \mathrm{~km}$. The chosen spectral band, near $655 \mathrm{GHz}$, contains a dense group of strong $\mathrm{O}_{3}$ lines suitable for exploiting the small amount of wind information in stratospheric spectra. Using both sidebands of the heterodyne receiver, a large number of chemical species will be measured, including $\mathrm{O}_{3}$ isotopologues, $\mathrm{H}_{2} \mathrm{O}, \mathrm{HDO}, \mathrm{HCl}, \mathrm{ClO}, \mathrm{N}_{2} \mathrm{O}, \mathrm{HNO}_{3}, \mathrm{NO}$, $\mathrm{NO}_{2}, \mathrm{HCN}, \mathrm{CH}_{3} \mathrm{CN}$ and $\mathrm{HO}_{2}$. This paper presents a simulation study that assesses measurement performance. The line-of-sight winds are retrieved between 30 and $90 \mathrm{~km}$ with the best sensitivity between 35 and $70 \mathrm{~km}$, where the precision $(1 \sigma)$ is $5-10 \mathrm{~m} \mathrm{~s}^{-1}$ for a single scan. Similar performance can be obtained during day and night conditions except in the lower mesosphere, where the photo-dissociation of $\mathrm{O}_{3}$ in daytime reduces the sensitivity by $50 \%$ near $70 \mathrm{~km}$. Profiles of $\mathrm{O}_{3}, \mathrm{H}_{2} \mathrm{O}$ and temperature are retrieved with high precision up to $50 \mathrm{~km}(<1 \%,<2 \%, 1 \mathrm{~K}$, respectively). Sys-
\end{abstract}

tematic errors due to uncertainties in spectroscopic parameters, in the radiometer sideband ratio and in the radiance calibration process are investigated. A large wind retrieval bias of $10-30 \mathrm{~m} \mathrm{~s}^{-1}$ between 30 and $40 \mathrm{~km}$ could be induced by the air-broadening parameter uncertainties of $\mathrm{O}_{3}$ lines. This highlights the need for good knowledge of these parameters and for studying methods to mitigate the retrieval bias.

\section{Introduction}

Millimeter and sub-millimeter (MM and SMM) limb sounders have been successfully used for more than 2 decades to probe the atmospheric composition and the temperature from the upper troposphere to the lower thermosphere (Waters et al., 1993; Murtagh et al., 2002; Waters et al., 2006; Kikuchi et al., 2010). The first generation of Millimeter Limb Sounder (MLS) provided unique observations of $\mathrm{ClO}, \mathrm{O}_{3}, \mathrm{H}_{2} \mathrm{O}$ and $\mathrm{HNO}_{3}$ allowing, for instance, a better understanding of the physical and chemical processes leading to the northern high-latitude $\mathrm{O}_{3}$ depletion (Waters et al., 1993). Subsequent SMM limb sounders have enabled monitoring of the middle atmosphere $(15-110 \mathrm{~km})$ almost without interruption since the first MLS and have significantly contributed to the current middle-atmospheric measurement database (Hegglin and Tegtmeier, 2017). However, no successor missions are currently planned, and there is a risk of an observation gap in the near future (Livesey and Santee, 2017). 
The benefits of such observations are manifold. The thermal emission spectrum at MM and SMM wavelengths is rich in isolated spectral lines from asymmetric molecules and molecular oxygen. Some important chemical species, such as $\mathrm{HO}_{2}$ and $\mathrm{ClO}$, have their clearest signals in this region of the spectrum (Urban et al., 2005; Khosravi et al., 2013; Sagawa et al., 2013; Millán et al., 2015). The $\mathrm{O}_{2}$ lines give temperature and pressure, and the limb geometry provides a suitable vertical resolution for describing the middle atmosphere. Molecules are sensed in the thermal equilibrium state with no diurnal difference in the measurement performance, and measurements are not perturbed by stratospheric polar clouds and aerosols. Furthermore, the technology is mature, allowing sounders to operate over a period of longer than a decade. Methods have already been developed for improving the horizontal resolution with tomographic observations (Livesey et al., 2006; Christensen et al., 2015) and for obtaining very high signal-to-noise ratios using $4 \mathrm{~K}$ cryogenic cooling (Kikuchi et al., 2010).

Modeling middle-atmospheric major dynamical phenomena such as vertically propagating tidal waves, high-latitude sudden-stratospheric warming and equatorial quasi-biennial oscillation is still challenging (Limpasuvan et al., 2012; Newman et al., 2016; Orsolini et al., 2017; Sakazaki et al., 2018). Wind is one of the primary parameters for describing the physical state of the atmosphere, but models have difficulties in reproducing it where the atmospheric flow cannot be described by the geostrophic approximation, such as in the equatorial region, where the Coriolis force is weak and in the upper stratosphere and mesosphere, where waves and tides tend to dominate the wind fields (Baron et al., 2013b; Le Pichon et al., 2015; Kawatani et al., 2016; Duruisseau et al., 2017; Rüfenacht et al., 2018). As climate and weather models increase their vertical range to encompass more of the stratosphere and mesosphere, the need for measurements to improve the accuracy of models in this region, and hence at lower altitudes, can be expected to rise (Baldwin et al., 2003, 2010; Hoppel et al., 2008; Gerber et al., 2012).

Only the High Resolution Doppler Imager (HRDI) on the Upper Atmosphere Research Satellite (1991-2005) was able to measure horizontal winds over the stratosphere and mesosphere (Ortland et al., 1996), and current spaceborne sensors are not able to measure wind accurately below $90 \mathrm{~km}$ (Shepherd, 2015).

Ground-based stations do not cover the globe uniformly and most of the data are limited to heights below $30 \mathrm{~km}$ (Ishii et al., 2017) or above $70 \mathrm{~km}$ (Baumgarten, 2010). However recent efforts have been made to close this altitude gap (Baumgarten, 2010; Rüfenacht et al., 2014; Le Pichon et al., 2015; Blanc et al., 2018).

Providing wind data in the middle atmosphere from space is one of the challenges for future missions. In August 2018, the European Space Agency will launch the Atmospheric Dynamics Mission (ADM) Aeolus equipped with a wind lidar to demonstrate the feasibility of such measure- ments (Stoffelen et al., 2005). However lidar is well suited for measuring wind in the troposphere but has poor precision above $20-30 \mathrm{~km}$ (Ishii et al., 2017). The Stratospheric Wind Interferometer For Transport studies (SWIFT) instrument has been proposed by the Canadian Space Agency for deriving winds between 15 and $45 \mathrm{~km}$ from $\mathrm{O}_{3}$ infra-red emission lines (Rahnama et al., 2013). The launch was originally planned for 2010 but it is now very uncertain.

The potential of MM/SMM limb sounders for measuring winds has been demonstrated with line-of-sight wind retrievals between 70 and $90 \mathrm{~km}$ from the MLS $\mathrm{O}_{2}$ line (Wu et al., 2008) and between 30 and $80 \mathrm{~km}$ from $\mathrm{O}_{3}$ and $\mathrm{HCl}$ lines measured with Superconducting Submillimeter-Wave Limb-Emission Sounder (SMILES) (Baron et al., 2013b). Wind is one of the main parameters studied by SMILES-2 that has been proposed to the Japan Aerospace Exploration Agency (JAXA) (Ochiai et al., 2017). SMILES-2 is a large instrument $(>500 \mathrm{~kg}$ ), which uses cryogenic SMM and $\mathrm{THz}$ receivers designed for very sensitive observations between 15 and $150 \mathrm{~km}$. If the project is approved this year, the launch will be near 2025. Two smaller instruments are under consideration for satellite launch as early as 2020-2022. Wu et al. (2016) propose a small instrument for measuring the atomic oxygen line at $2.06 \mathrm{THz}$ in order to retrieve its abundance as well as temperature and wind in the lower thermosphere. However this instrument cannot provide stratospheric and lower mesospheric information. The second proposal is the Stratospheric Inferred Winds (SIW) instrument. It is a small and low-cost satellite instrument being studied as part the Swedish InnoSat program (Lindberg, 2016; Murtagh, 2016). This program has planned to launch a scientific instrument every 2 years, and SIW has been selected for the second launch near 2022. It will observe the middle atmosphere (15$90 \mathrm{~km}$ ) for a period expected to be at least 2 years, and will provide horizontal wind vectors within $30-90 \mathrm{~km}$. The other primary products are the profiles of temperature, $\mathrm{O}_{3}, \mathrm{H}_{2} \mathrm{O}$ and more than a dozen of other chemical species. With this mission it will be possible to ensure the continuous monitoring of the middle atmosphere, avoiding an SMM measurement gap.

In this paper we present a simulation study that assesses the potential of SIW. A special focus is put on the main parameters: wind, temperature, $\mathrm{O}_{3}$ and $\mathrm{H}_{2} \mathrm{O}$ that are derived from the strongest lines in the selected spectral bands. Section 2 describes the mission and the observation technique. The measurement simulation and the retrieval method are explained in Sects. 3 and 4, respectively. The measurement performance is discussed in Sect. 5 and concluding remarks are given in the final section. 


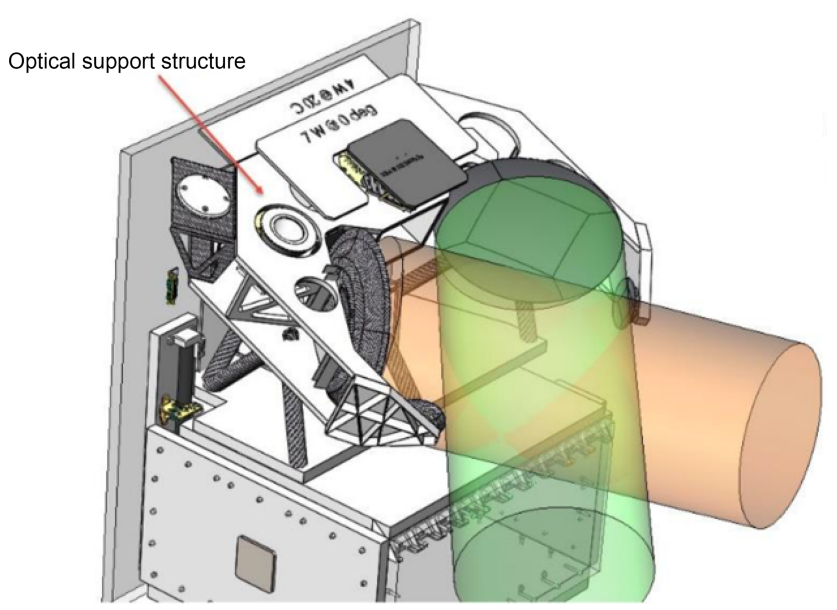

Figure 1. View of the InnoSat satellite. The box in the lower part is the platform service module. Above it is the scientific payload including the two antennas. The field of views are represented with green and beige colors (from Omnisys Instruments).

\section{Mission description}

\subsection{Observation and instrument characteristics}

The scientific payload (Fig. 1) and observation characteristics are summarized in Table 1. This is the proposed setting which can still be slightly modified. The platform will be set at a sun-synchronous polar orbit at an altitude of $550 \mathrm{~km}$. It will fly near the terminator, crossing the equatorial ascending node at 18:00 local time (LT). Atmospheric observations will be performed toward the night side using two antennas facing perpendicularly to each other with angles from the satellite velocity of 45 and $135^{\circ}$, respectively. The antennas will point toward close air masses with few minutes delay (Fig. 2). They are fixed on the platform and the whole satellite will nod up and down in order to scan the limb alternatively upward and downward from about 15 to $90 \mathrm{~km}$. The forward antenna is used during the upward scans and the aftward one during the downward scans. With this choice, the horizontal displacement of the tangent point during a vertical scan is less than $300 \mathrm{~km}$, the vertical motion of the line of sight partly counterbalancing the satellite motion. Using the line-of-sight (LOS) winds retrieved with the two antennas over close regions allows us to derive the meridional and zonal wind components (Appendix A). The separation between the LOS wind profiles is less than $400 \mathrm{~km}$.

The signals from the antennas are alternatively sent to a single radiometer passively cooled to $70 \mathrm{~K}$ below the ambient temperature, and analyzed with an autocorrelator spectrometer. The heterodyne radiometer operates in double-sideband (DSB) mode yielding to the superposition in the measured spectrum of the two image bands with respect to the local oscillator (LO). The bandwidth and resolution are $8 \mathrm{GHz}$ and $1 \mathrm{MHz}$, respectively.
Table 1. Characteristics of the SIW payload and observations. The relationship between tangent height and LOS angle is derived for an Earth radius of $6370 \mathrm{~km}$ and a satellite altitude of $550 \mathrm{~km}$ above the geoid.

\begin{tabular}{ll}
\hline Payload dimensions & $40 \times 70 \times 40 \mathrm{~cm}$ \\
Payload mass/power & $17 \mathrm{~kg} / 47 \mathrm{~W}$ \\
Antenna diameter & $30 \mathrm{~cm}$ \\
\hline Satellite altitude & $500-600 \mathrm{~km}$ \\
Orbit inclination & $98^{\circ}$ (sun synchronous) \\
Latitude range & $65^{\circ} \mathrm{S}-82^{\circ} \mathrm{N}$ \\
Local time of ascending node & $18: 00$ \\
Scan altitude & $10-90 \mathrm{~km}$ \\
LOS nadir angle & $67.25-69.03^{\circ}\left(1.78^{\circ}\right)$ \\
Scan velocity & $0.05^{\circ} \mathrm{s}^{-1}\left(35 \mathrm{~s} \mathrm{scan}^{-1}\right)$ \\
Spectrum integration time & $0.5 \mathrm{~s}(1.14 \mathrm{~km})$ \\
Antenna vertical FOV & $5 \mathrm{~km}$ \\
\hline DSB system temperature & $1000-1200 \mathrm{~K}$ \\
ACS Bandwidth & $8 \mathrm{GHz}$ \\
ACS resolution & $1 \mathrm{MHz}$ \\
LO frequency & $638.075 \mathrm{GHz}(\lambda=0.47 \mathrm{~mm})$ \\
IF frequency & $10.975-18.975 \mathrm{GHz}$ \\
Frequency $\Leftrightarrow$ velocity & $1 \mathrm{~m} \mathrm{~s}-1 \Leftrightarrow 2 \mathrm{kHz}$ \\
\hline
\end{tabular}

* Tangent point vertical displacement.

The strategy for acquiring the calibration data has yet been definitively decided upon, and it will probably be optimized in the future. Currently the plan is as follows. A calibration load onboard the platform (black body at ambient temperature) is viewed at the bottom and top of each scan during the turnaround. While limb scanning, the atmosphere and cold sky are observed alternatively with an integration time of $0.5 \mathrm{~s}$ each. Hence, atmospheric spectra are obtained every $2.3 \mathrm{~km}$ with an effective vertical resolution of about $5 \mathrm{~km}$.

\subsection{Spectral bands}

The measured spectrum is composed of molecular lines spectrally resolved (Fig. 3). Using a radiative transfer model, they are inverted to retrieve geophysical information. Volume mixing ratio (VMR) and temperature are retrieved from their amplitude, whereas pressure and line-of-sight wind are retrieved from the width and the frequency position of the lines, respectively.

The Doppler shift induced by the LOS wind $(2 \mathrm{kHz}$ for $1 \mathrm{~m} \mathrm{~s}^{-1}$ ) is small compared to the line broadening (1$100 \mathrm{MHz}$ ). This gives a very weak signal to exploit, especially in the lower stratosphere. Baron et al. (2013a) have shown that the spectral region near $655 \mathrm{GHz}$ is the most suitable for measuring wind with the current hardware. It contains a dense group of strong $\mathrm{O}_{3}$ lines (second row of Fig. 3), that increases by at least a factor of 2 the wind measurement sensitivity between 40 and $70 \mathrm{~km}$ compared to retrievals performed with a band of similar characteristics but located at 

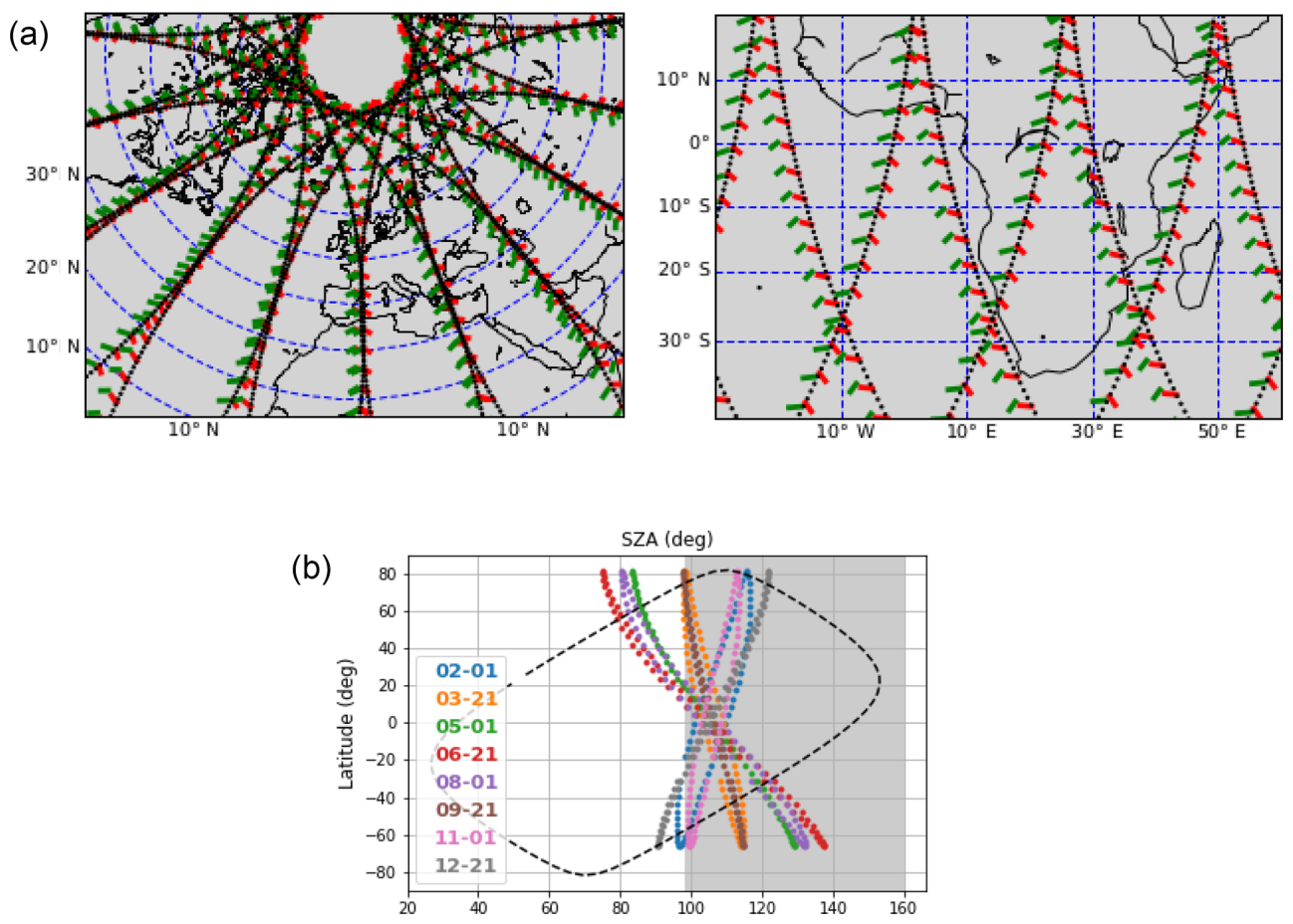

Figure 2. Panel (a) shows the footprints of the forward $\left(45^{\circ}\right)$ and aftward $\left(135^{\circ}\right)$ views over a $24 \mathrm{~h}$ period. The forward antenna is used during the upward scans (red lines) and the aftward one during the downward scans (green lines). The first tangent point of the upward scans are located on the black-dotted lines. Panel (b) shows the solar zenith angles with respect to latitudes for various days representative of the seasonal variation (colored dots) together with those of the Aura MLS data (DJF, 2011) used in the simulations (dashed line). The shaded area shows the nighttime measurements in the mesosphere, where the $\mathrm{O}_{3}$ diurnal variation is the strongest.

any other frequency under $800 \mathrm{GHz}$. This band also allows us to retrieve temperature with good precision in the stratosphere without measuring an $\mathrm{O}_{2}$ line.

The local oscillator frequency has been carefully selected in order to include as many as possible spectral lines and to reduce the line superposition from both sidebands. Hence lines of chemical species such as $\mathrm{HCN}(620.3 \mathrm{GHz}), \mathrm{H}^{37} \mathrm{Cl}$ $(625.0 \mathrm{GHz}) \mathrm{H}^{35} \mathrm{Cl}(625.9 \mathrm{GHz}),{ }^{35} \mathrm{ClO}(649.5 \mathrm{GHz}), \mathrm{NO}$ $(651.1 \mathrm{GHz})$ and $\mathrm{N}_{2} \mathrm{O}(652.8 \mathrm{GHz})$ are clearly visible. A strong $\mathrm{H}_{2} \mathrm{O}$ line is located at $620.7 \mathrm{GHz}$ but very close to an $\mathrm{O}_{3}$ line with similar strength. Lines from around twenty molecules are available though some are very weak such as $\mathrm{H}_{2} \mathrm{CO}, \mathrm{CH}_{3} \mathrm{Cl}$ or $\mathrm{BrO}$. Finally let us note that most of the lines where intermediate frequency (IF) of $>14 \mathrm{GHz}$ have already been measured with Aura MLS and JEM/SMILES.

\section{Measurement modeling}

\subsection{Radiative transfer and instrument}

The signal is a spectral and spatial average of specific intensities $\left(\mathrm{W} \mathrm{m}^{-2} \mathrm{sr}^{-1} \mathrm{~Hz}^{-1}\right)$ over narrow instrumental functions. It is expressed in the so-called Rayleigh-Jeans bright- ness temperature $T_{\mathrm{b}}$ equal to (Urban et al., 2004)

$$
\begin{aligned}
T_{\mathrm{b}}\left(\theta_{j}, \vartheta_{k}\right) & =\kappa_{\mathrm{b}} \int_{\Delta \vartheta} \mathrm{d} \vartheta g^{\mathrm{sp}}\left(\vartheta-\vartheta_{k}\right)\left\{w_{\mathrm{lsb}}(\vartheta) \int_{\Delta \theta} G_{\mathrm{e}}^{\mathrm{ant}}\right. \\
& \left(\theta-\theta_{j}, v_{\mathrm{lo}}-\vartheta\right) I\left(\theta, \nu_{\mathrm{lo}}-\vartheta\right) \mathrm{d} \theta \\
& +\left(1-w_{\mathrm{lsb}}(\vartheta)\right) \int_{\Delta \theta} G_{\mathrm{e}}^{\mathrm{ant}}\left(\theta-\theta_{j}, \nu_{\mathrm{lo}+\vartheta}\right) \\
& \left.I\left(\theta, \nu_{\mathrm{lo}}+\vartheta\right) \mathrm{d} \theta\right\},
\end{aligned}
$$

where $\vartheta_{k}$ is the frequency of the $k$ th spectral component of the measurement, $\theta_{j}$ is the mean nadir angle during the measurement integration time of the $j$ th spectra of the scan, and $I$ is the specific intensity. The specific intensity is integrated along a LOS as that shown in Fig. 4. The LOS is characterized by the altitude of the tangent point, the angle with the meridional direction $\phi_{\mathrm{n}}$ and narrow ranges over which the atmosphere is considered homogeneous. The heterodyne receiver is sensitive to atmospheric radiation at frequencies $v_{\mathrm{lo}} \pm \vartheta$, where $\nu_{\mathrm{lo}}$ and $\vartheta$ are the local oscillator and intermediate frequencies (Table 1). The instrumental functions are the spectrometer channel response $g_{\mathrm{sp}}\left(\mathrm{Hz}^{-1}\right)$, the relative weight of the radiometer sidebands $w_{\text {lsb }}$ and the effective antenna pattern $G_{\mathrm{e}}^{\text {ant }}$. The parameter $\kappa_{\mathrm{b}}$ is the Rayleigh-Jeans 

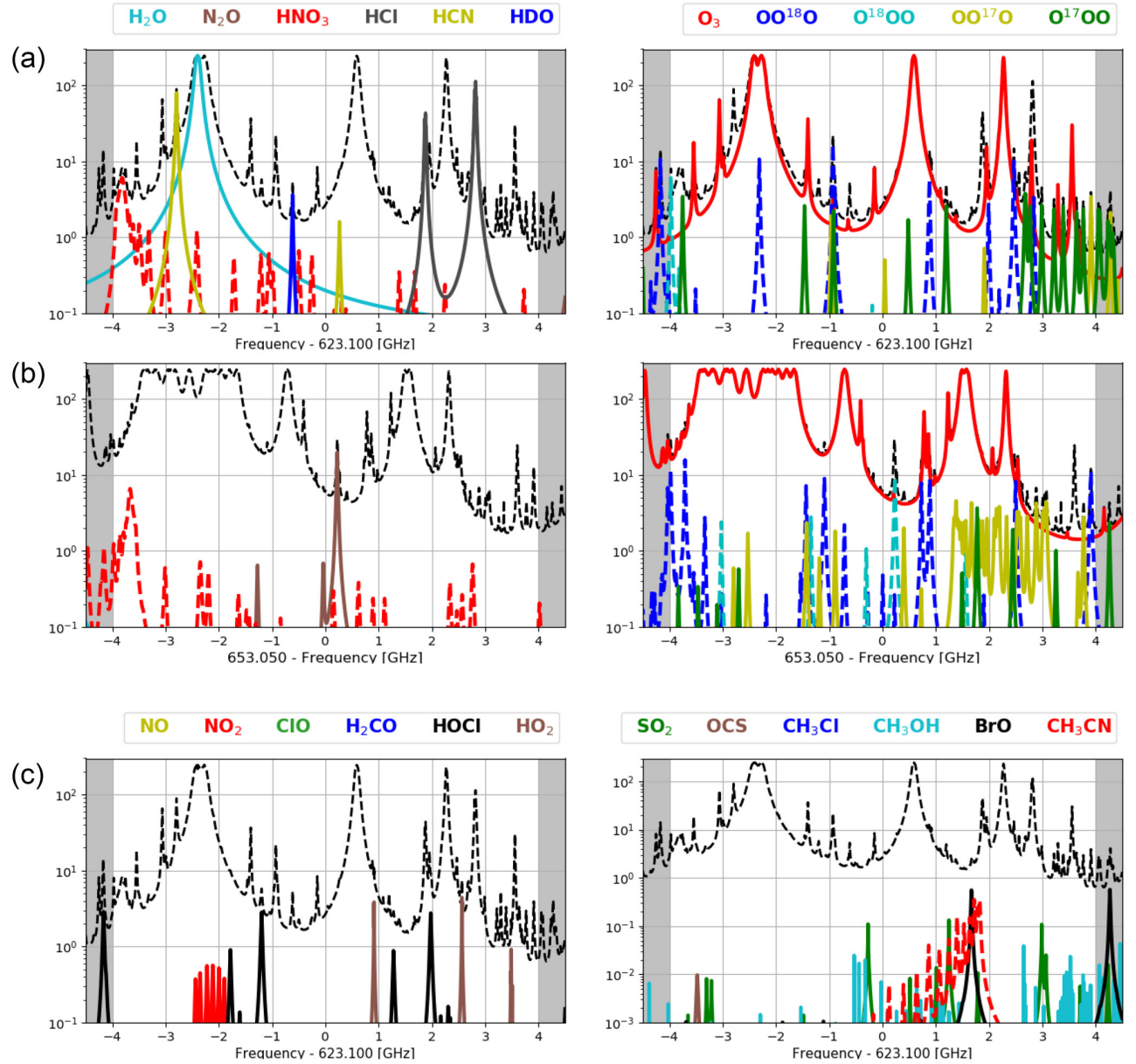

(d)
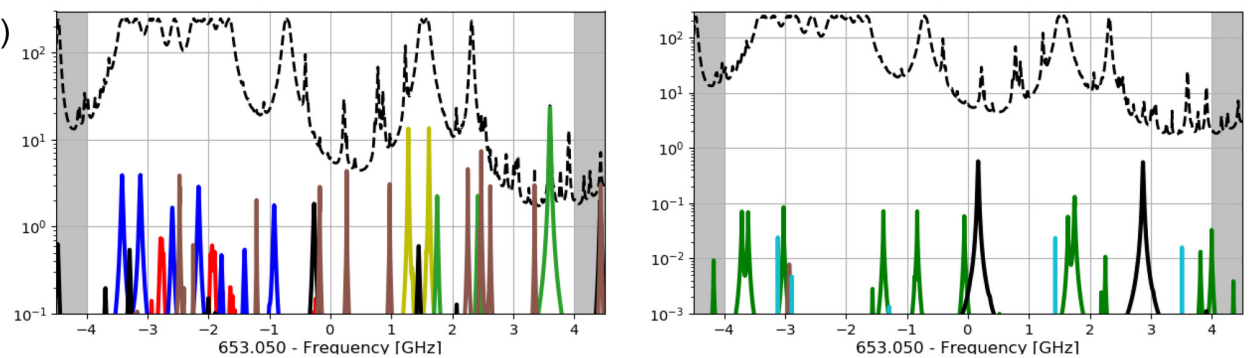

Figure 3. Contributions of the most relevant chemical species to the SIW spectrum. More that 20 molecules are shown in four groups of two panels. In each group, the upper panel shows the lower sideband spectrum (dashed black lines) with a central frequency of $623.1 \mathrm{GHz}$ and the lower panel shows the upper sideband spectrum with a central frequency of $653.05 \mathrm{GHz}$. The colored lines are single-molecule spectra. Grey-shaded areas are outside the bandwidth. The tangent height is $35 \mathrm{~km}$ and frequencies are ordered according to the intermediate frequencies. The intensity is given in brightness temperature ( $y$ axis).

factor, used to convert the intensity into brightness temperature:

$\kappa_{\mathrm{b}}=\frac{c^{2}}{2 k_{b} v_{\mathrm{lo}}^{2}}$,

where $c=2.997924 \times 10^{8} \mathrm{~m} \mathrm{~s}^{-1}$ is the speed of light in vacuum and $k_{\mathrm{b}}=1.380662 \times 10^{-23} \mathrm{~J} \mathrm{~K}^{-1}$ the Boltzmann constant. The spectrometer channel response is assumed to be Gaussian with a full width at half maximum (FWHM) of
$1 \mathrm{MHz}$. Given that the altitude range scanned during the spectrum integration is small compared to the static-antenna vertical resolution ( $1.1 \mathrm{~km}$ and $5 \mathrm{~km}$, respectively), the effective antenna pattern including the vertical scan is approximated by a Gaussian function with the FWHM:

$$
\sigma_{e}^{\mathrm{ant}}=\sqrt{\left(\frac{1.22}{D} \frac{c}{v_{\mathrm{lo}}}\right)^{2}+\left(\dot{\theta} \Delta_{T}\right)^{2}},
$$


where $D(\mathrm{~m})$ is the antenna diameter, $\dot{\theta}\left(\mathrm{rad} \mathrm{s}^{-1}\right)$ is the vertical scan velocity and $\Delta_{T}$ is the spectrum integration time. The antenna sidelobes are also neglected. These approximations have negligible impacts on this study. A constant spectral sideband weight is used, $w_{\mathrm{lsb}}(\vartheta)=0.5$. The integrals in Eq. (1) are computed over ranges $\Delta \theta$ and $\Delta \vartheta$ set to 3 times the FWHM of their corresponding response functions.

\subsection{Specific intensity and wind}

The specific intensity is computed using the radiative transfer equation:

$$
\begin{aligned}
I(\theta, v) & =\int_{s=0}^{s_{r}} B_{v}(s) K_{v}\left(s,\left\{v_{a}(s)\right\}_{\text {lines }}\right) \\
& \exp \left(-\int_{s^{\prime}=s}^{s_{r}} K_{v}\left(s,\left\{v_{a}\left(s^{\prime}\right)\right\}_{\text {lines }}\right) \mathrm{d} s^{\prime}\right) \mathrm{d} s,
\end{aligned}
$$

where $s$ indicates the position on the LOS, $B$ is the Planck function $\left(\mathrm{W} \mathrm{m}^{-2} \mathrm{sr}^{-1} \mathrm{~Hz}^{-1}\right)$ and $K\left(\mathrm{~m}^{-1}\right)$ is the absorption coefficient. The background cosmic radiation $\left(T_{\mathrm{b}} \approx 1 \mathrm{mK}\right)$ is neglected. The absorption coefficient is computed with a line-by-line model and continua models (Urban et al., 2004). The spectroscopic parameters describing the molecular lines are taken from the HITRAN catalog (Rothman et al., 2009) except those for $\mathrm{BrO}, \mathrm{CH}_{3} \mathrm{Cl}$ and $\mathrm{CH}_{3} \mathrm{CN}$, which are not available in HITRAN, and are thus taken from the Jet Propulsion Laboratory catalog (Pickett et al., 1998). The frequency of the spectral lines viewed from the receiver $\left(\left\{v_{a}(s)\right\}_{\text {lines }}\right)$ depends on the mean relative motion of the molecules with respect to the receiver, i.e., satellite velocity and wind. The effect of the Doppler on the Planck function is neglected. The line frequency is also shifted by the atmospheric pressure but this effect is small above $25 \mathrm{~km}$ where winds are measured. For the $\mathrm{H}_{2} \mathrm{O}$ line at $620 \mathrm{GHz}, 2 \%$ error in the shift parameter corresponds to an error of $2 \mathrm{~m} \mathrm{~s}^{-1}$ at $10 \mathrm{hPa}$. The shift on $\mathrm{O}_{3}$ lines should be smaller but the information is not available in HITRAN and further studies are needed to infer it.

A spherical Earth is assumed for assessing the impacts of all the parameters contributing to the line Doppler shift. At a height $z_{i}$ and for a LOS nadir angle $\theta$, the line-apparent frequency is (Kursinski et al., 1997)

$$
\begin{aligned}
& v_{a}\left(\theta, z_{i}\right)= \\
& v_{0}\left(\begin{array}{c}
{\left[V\left(z_{i}\right) \cos \left(\phi_{\mathrm{n}}\right)+\right.} \\
1-\frac{\left.\left(U\left(z_{i}\right)+\omega_{\mathrm{e}} R_{\mathrm{e}} \cos (\Lambda)\right) \sin \left(\phi_{\mathrm{n}}\right)\right] \sin \left(\alpha_{i}\right)}{c} \\
\left.+\frac{W \cos \left(\alpha_{i}\right)}{c}+\frac{V_{\mathrm{sat}} \cos (\phi) \sin \theta}{c}\right)
\end{array}\right.
\end{aligned}
$$

where $v_{0}(\mathrm{~Hz})$ is the rest frequency of the transition, $V_{\text {sat }}$ is the satellite velocity with respect to a fixed frame attached to the Earth center, $(U, V, W)$ is the 3-D wind velocity defined with respect to the Earth surface and $\omega_{\mathrm{e}}, \Lambda$ and $R_{\mathrm{e}}$ are the Earth rotation angular velocity $\left(\mathrm{rad} \mathrm{s}^{-1}\right)$, the latitude and the geoid radius at the position $i$. The LOS nadir angle at $z_{i}$ is $\alpha_{i}$, and $\phi_{\mathrm{n}}$ is the angle between the LOS and the north direction (Fig. 4).

At the tangent height point $(i=0), \alpha_{0}=90^{\circ}$ and the Doppler shift $\delta v\left(\theta, z_{0}\right)$ is

$$
\begin{aligned}
\delta v\left(\theta, z_{0}\right) & =-\frac{v_{0}}{c}\left(V_{\mathrm{los}}\left(z_{0}\right)+\omega_{\mathrm{e}} R_{\mathrm{e}} \cos (\Lambda) \sin \left(\phi_{\mathrm{n}}\right)\right. \\
& \left.-V_{\text {sat }} \cos (\phi) n_{0} \frac{z_{0}+R_{\mathrm{e}}}{z_{\mathrm{r}}+R_{\mathrm{e}}}\right),
\end{aligned}
$$

where $z_{\mathrm{r}}$ is the receiver height, $n_{0}$ is the refractive index at the tangent point, $\sin (\theta)=n_{0} \frac{z_{0}+R_{\mathrm{e}}}{z_{\mathrm{r}}+R_{\mathrm{e}}}$ and $V_{\mathrm{los}}$ is the LOS component of the horizontal wind:

$V_{\mathrm{los}}\left(z_{0}\right)=V\left(z_{0}\right) \cos \left(\phi_{\mathrm{n}}\right)+U\left(z_{0}\right) \sin \left(\phi_{\mathrm{n}}\right)$.

At the Equator and for the forward LOS, the Doppler shifts due to the satellite velocity and to the Earth rotation are $\approx-8 \mathrm{MHz}\left(+4000 \mathrm{~m} \mathrm{~s}^{-1}\right)$ and $\mp 0.74 \mathrm{MHz}\left( \pm 370 \mathrm{~m} \mathrm{~s}^{-1}\right)$, respectively. In order to simplify the calculations, we consider the case of a pseudo-LOS wind profile which, unlike a real one, induces a Doppler shift $\delta v(z)=-v_{0} / c V_{\text {plos }}(z)$ that is independent of the angles $\alpha_{i}$ and Earth rotation, and includes the vertical changes due to the satellite velocity:

$V_{\mathrm{plos}}(z)=V_{\mathrm{los}}(z)-V_{\mathrm{sat}} \cos (\phi) n_{z}\left(\frac{z-50 \mathrm{~km}}{z_{\mathrm{r}}+R_{\mathrm{e}}}\right)$.

At the tangent point, the pseudo-wind induced the same Doppler shift as that given in Eq. (5) to within the same constant over the full vertical scan. The constant includes the Earth rotation effects and most of the satellite velocity ones. The terms embedded in this constant are known with a precision better than $1 \mathrm{~m} \mathrm{~s}^{-1}$ using the star trackers and GPS data onboard the satellite. Such a setting is chosen to yield the satellite-velocity-induced Doppler shift to zero at $z=50 \mathrm{~km}$, center of the vertical scan.

The pseudo-wind approximation induces errors in the lineapparent frequency at positions on the LOS other than the tangent point. These errors are smaller than $10 \mathrm{~cm} \mathrm{~s}^{-1}$ and have negligible impacts on the retrievals. Indeed, VMR and temperature retrievals are not sensitive to small frequency errors, and regarding wind retrieval, the information is extracted from optically thin measurements which are characterized by narrow specific-intensity weighting functions peaking at the tangent point.

\subsection{Calibration and measurement noise}

The raw intensity delivered by the spectrometer is expressed as (Olberg et al., 2003)

$$
C_{i, j}=G_{i, j}\left[T_{\mathrm{sys}}(i, j)+\eta_{x} T_{\mathrm{b}}(i, j)+\left(1-\eta_{x}\right) T_{\mathrm{so}}(i)\right],
$$




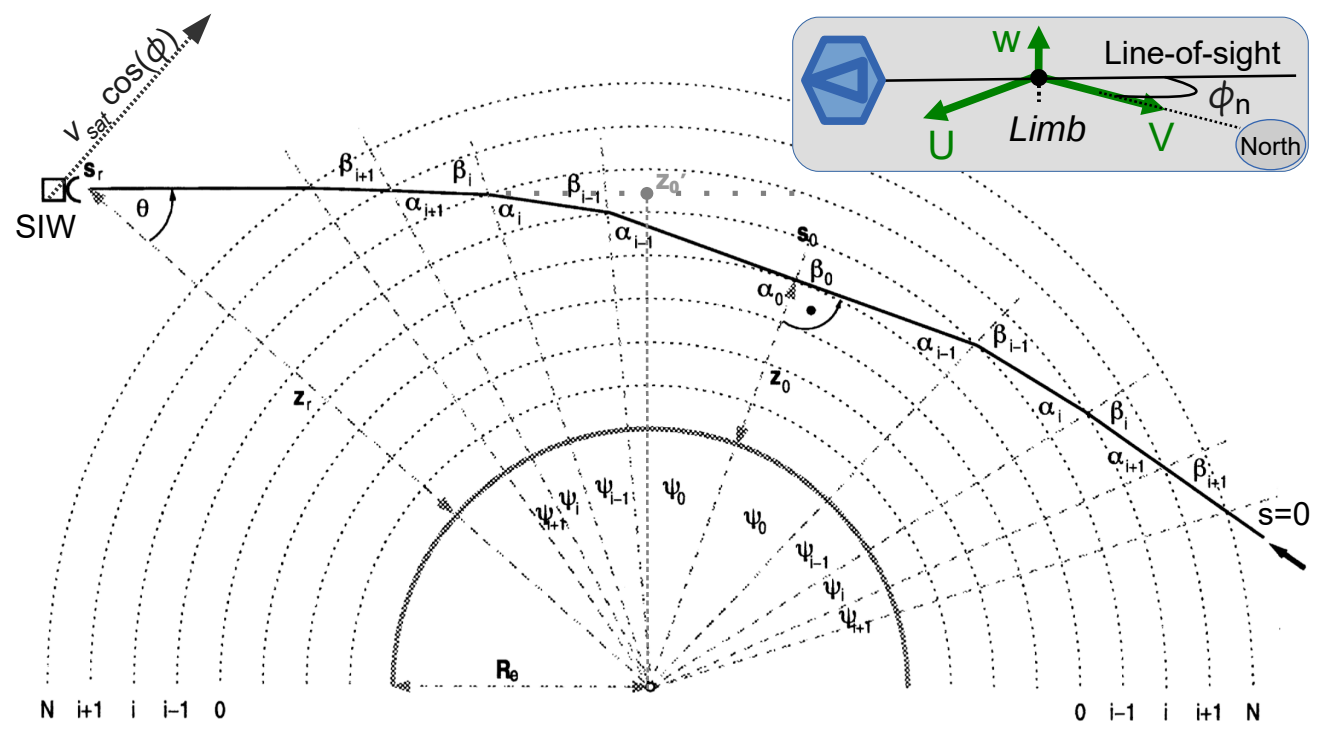

Figure 4. Limb sounding geometry for a refracted line of sight (full line) and a non-refracted one (dashed line). The panel on the right-upper corner shows the orientation of the LOS with respect to the wind components at the tangent point. Figure is adapted from Urban et al. (2004).

where $i$ and $j$ are the tangent height and frequency indices, $T_{\text {sys }}$ is the double sideband system temperature, $T_{\text {so }}$ is the mean brightness-temperature introduced by the optics spillover, $\eta_{x}$ is the efficiency of the integrated antenna $(x=a)$ or hot-load horn $(x=c)$ and $G$ is the radiometric gain. The last term is

$G_{i, j}=g_{i, j}\left(1-\alpha\left\langle C_{i, j}\right\rangle\right)$,

where \langle\rangle denotes the average over the frequencies $j$ and $\alpha$ is a positive coefficient to account for a non-linear response of the radiometer (Ochiai et al., 2013). The doublesideband system temperature of SIW is expected to be about $1100 \mathrm{~K}$ (Omnisys, private communication). The signal intensity is calibrated using the emissions from the cold sky with a Rayleigh-Jeans temperature $T_{\mathrm{c}} \approx 10^{-3} \mathrm{~K}$, and from an ambient temperature hot load (Rayleigh-Jeans temperature $T_{\mathrm{h}} \approx 250 \mathrm{~K}$ ) measured between two scans. Assuming a linear response of the radiometer and using $T_{\mathrm{c}} \ll T_{\mathrm{h}}$, the radiometer gain is derived as (Olberg et al., 2003)

$\widehat{G}_{j}=\frac{\bar{C}_{h}(j)-\bar{C}_{c}(j)}{\epsilon T_{\mathrm{h}}}$,

where $\epsilon$ is the hot-load emissivity, and $C_{\mathrm{h}}$ and $C_{\mathrm{c}}$ are the receiver raw outputs for the hot load and cold sky. The upper bars ${ }^{-}$indicate that an average value over the whole scan is used. The brightness temperature of the atmospheric signal is then

$\widehat{T_{\mathrm{b}}}(i, j)=\frac{C_{\mathrm{atm}}(i, j)-\bar{C}_{\mathrm{c}}^{\prime}(i, j)}{\eta_{\mathrm{a}} \widehat{G}_{i, j}}+\operatorname{offset}_{i}$,

where $C_{\text {atm }}$ is the receiver output when the atmosphere is viewed and $\bar{C}_{\mathrm{c}}^{\prime}(i, j)$ is the cold-sky output interpolated at the
$C_{\text {atm }}$ time. We consider that during the scan, the atmosphere and cold sky are viewed alternatively during $0.5 \mathrm{~s}$ each. The second term of the equation is a tangent-height-dependent offset induced by the antenna spillover. Such radiance offset is retrieved together with the geophysical information and it is not considered as a retrieval error source. The brightness temperature error from the radiometer noise and the calibration model is

$$
\begin{aligned}
\delta \widehat{T}_{\mathrm{b}}(i, j) & =\frac{\delta C_{\mathrm{atm}}(i, j)}{\widehat{G}_{j}}+\frac{\delta \bar{C}_{\mathrm{c}}^{\prime}(i, j)}{\widehat{G}_{j}}+\widehat{T}_{\mathrm{b}}(i, j) \frac{\delta \widehat{G}_{j}}{\widehat{G}_{j}} \\
& +\widehat{T}_{\mathrm{b}}(i, j) \frac{\delta \eta_{\mathrm{a}}}{\eta_{\mathrm{a}}}+e_{\mathrm{NL}}(i, j) \\
& =\epsilon_{\mathrm{atm}}(i, j)+\epsilon_{\overline{\mathrm{c}}}^{\prime}(i, j)+\left(\epsilon_{\overline{\mathrm{h}}}(j)+\epsilon_{\overline{\mathrm{c}}}(j)\right) \\
& \beta_{\mathrm{h}}(i, j)+\left(e_{\overline{\mathrm{h}}}+e_{\eta_{\mathrm{a}}}\right) \widehat{T}_{\mathrm{b}}(i, j)+e_{\mathrm{NL}}(i, j),
\end{aligned}
$$

where $\epsilon_{\mathrm{atm}}$ and $\epsilon_{\overline{\mathrm{c}}}^{\prime}$ are white noises of the atmospheric and cold-sky brightness temperatures (Eq. 11); $\epsilon_{\overline{\mathrm{c}}}$ and $\epsilon_{\overline{\mathrm{h}}}$ are those of the hot-load and cold-sky spectra in Eq. (10), and $\beta_{\mathrm{h}}=\frac{T_{\mathrm{b}}(i, j)}{\epsilon T_{\mathrm{h}}}$. The two last elements of the equation are systematic errors induced by relative errors $e_{\overline{\mathrm{h}}}$ and $e_{\eta_{\mathrm{a}}}$ on the hot-load emission $\left(\epsilon T_{\mathrm{h}}\right)$ and the antenna efficiency $\left(\eta_{\mathrm{a}}\right)$, and the error due to the receiver non-linearity $\left(e_{\mathrm{NL}}\right)$.

The noise standard deviation is given by the radiometric equation (Jarnot et al., 2006; Ochiai et al., 2013):

$\sigma_{t}(i, j)=\left[T_{\mathrm{sys}}^{\mathrm{dsb}}(i, j)+T_{\mathrm{b}}(i, j)\right] \sqrt{\frac{1}{w t}+\left(\frac{\Delta G}{G}\right)^{2}}$,

where $w(=1 \mathrm{MHz})$ is the noise equivalent bandwidth of spectrometer channel and $t$ is the observation time. The 
term $1 / w t$ describes a spectrally uncorrelated noise, while $(\Delta G / G)$ describes a fully spectrally correlated noise (Jarnot et al., 2006; Ochiai et al., 2013), that is, at first approximation, a radiance offset that is mitigated by the subtraction of the cold sky in Eq. (11). Considering the average and interpolation on the cold-sky and hot-load outputs, the covariance matrix describing the measurement noise is then:

$$
S_{y}\left(u, u^{\prime}\right)=\left\{\begin{array}{l}
\sigma_{a}^{2}+\sigma_{c}^{\prime 2} / 2+\left(\sigma_{c}^{2}+\sigma_{h}^{2}\right) \beta_{\mathrm{h}}^{2}(u) \\
\text { if } i=i^{\prime} \text { and } j=j^{\prime} \\
\sigma_{c}^{\prime 2} / 2+\left(\sigma_{c}^{2}+\sigma_{h}^{2}\right) \beta_{\mathrm{h}}(u) \beta_{\mathrm{h}}\left(u^{\prime}\right) \\
\text { if }\left|i-i^{\prime}\right|=1 \text { and } j=j^{\prime} \\
\left(\sigma_{c}^{2}+\sigma_{h}^{2}\right) \beta_{\mathrm{h}}(u) \beta_{\mathrm{h}}\left(u^{\prime}\right) \\
\text { if }\left|i-i^{\prime}\right|>1 \text { and } j=j^{\prime} \\
0 \\
\text { if } j \neq j^{\prime}
\end{array}\right.
$$

where $u=i \cdot N_{f}+j, u^{\prime}=i^{\prime} \cdot N_{f}+j^{\prime}$ and $N_{f}$ is the number of frequencies per spectrum. Here we consider an integration time of $2 \mathrm{~s}$ for the hot-load and cold-sky spectra in Eq. (10) (used for assessing $\sigma_{\mathrm{c}}$ and $\sigma_{\mathrm{h}}$ ). The time needed for acquiring the hot-load spectra is available between the termination of a scan and the beginning of the next one. Cold-sky spectra can be obtained in very various ways. A simple one is to construct them using the first four and last four cold-sky spectra measured during a scan.

The error $e_{\mathrm{NL}}$ due to the radiometer non-linear response, i.e., non-zero $\alpha$ in Eq. (9), is the difference between the true brightness temperature $T_{\mathrm{b}}$ and the calibrated one $\widehat{T_{\mathrm{b}}}$, computed as follows (Baron et al., 2011):

1. $G_{\text {cold }, i, j}$ is computed applying Eq. (8) to the coldsky view assuming $C_{\mathrm{c}}=1800 \mathrm{ADU}$ that is consistent with Odin/SMR (Olberg et al., 2003), $T_{\text {sys }}=1100 \mathrm{~K}$, $T_{\mathrm{b}}($ cold - sky $)=0 \mathrm{~K}$ and $\eta_{x}=1$. The value $g_{i, j}$ is then computed (Eq. 9).

2. $C_{\text {hot }}$ and $C_{\text {atm }}$ are computed given $T_{\text {hot }}=250 \mathrm{~K}$ and $T_{\mathrm{b}}$ using an iterative process initialized with $G_{\text {cold }}$ (Eqs. 8 and 9).

3. Finally, we compute $\widehat{G}\left(\right.$ Eq. 10), $\widehat{T_{\mathrm{b}}}\left(\right.$ Eq. 11) and $e_{\mathrm{NL}}=$ $\widehat{T_{\mathrm{b}}}-T_{\mathrm{b}}$.

\section{Retrieval errors}

\subsection{Reference atmosphere}

The measurement performance depends on the atmospheric state, which depends on the latitude, season and local time (for our calculations, we assume that the zonal variations of the mean atmospheric state are negligible). The most relevant parameters to take into account are the profiles of $\mathrm{O}_{3}, \mathrm{H}_{2} \mathrm{O}$, $\mathrm{HCl}$, temperature and pressure (or geopotential height). A zonal-mean climatology of these parameters has been built, covering all latitudes divided into 11 bins (Fig. 5). These climatologies are based on Aura MLS observations (v3.3) performed between 15 November 2009 and 15 February 2010. This period has been chosen because of the strong contrast between the winter-pole and summer-pole conditions that provides large meridional variations of atmospheric states. Moreover, it was characterized by a stable northern polar vortex, which was not affected by any strong perturbation (Kuttippurath and Nikulin, 2012). MLS observes in the moving direction from a sun-synchronous platform. The orbit inclination is $98^{\circ}$ from the equatorial plane. Each latitude is observed at two different local times, e.g., 01:45 and 13:45 LT at the Equator. These two LT are used to characterize the dayand nighttime conditions though it is daytime (nighttime) for both LT over the southern (northern) boreal latitudes (Fig. 2).

Bad data have been removed following the MLS user's guide documentation (Livesey et al., 2011), except for the data flagged with negative errors that are biased toward the MLS retrieval a-priori. Using such data allows us to span the altitude coverage of the profiles up to $110 \mathrm{~km}$ with information suitable for this study. Other molecules are taken from the Whole Atmosphere Community Climate Model (WACCM) (Marsh et al., 2013) and extracted at the climatology latitudes and LT. For $\mathrm{HOCl}, \mathrm{HCN}$ and $\mathrm{CH} 3 \mathrm{CN}$ only tropical profiles are used. Because of their relatively weak signal, their variabilities do not impact the overall measurement performance and only typical abundances are needed to discuss the relevance of the measurement.

\subsection{Retrieval method}

The simulations are performed with the radiative transfer and retrieval codes used in the SMILES research processing chain (Baron et al., 2011) which has been validated with real observations (Kasai et al., 2013). The retrieved state $\hat{\boldsymbol{x}}$ is a vector including all the unknown parameters of the forward model, namely the atmospheric vertical profiles, a radiance offset on each spectrum and a mean pointing angle offset of the whole scan. The atmospheric profiles are the volume mixing ratio (VMR) profiles of the chemical species, as well as those of temperature and LOS wind.

The retrieval altitudes range from 10 to $90 \mathrm{~km}$, a range fully encompassed within the scan range $(10-90 \mathrm{~km})$. The grid resolution is $5 \mathrm{~km}$ corresponding to the effective vertical field-of-view of the instrument. Such a setting allows us to perform retrievals using a simple linear least-squares method with weak regularization. The retrieved vector is given by the equation:

$\hat{\boldsymbol{x}}=\boldsymbol{x}_{0}+\left(\boldsymbol{K}^{T} \boldsymbol{S}_{\mathrm{d}, y}^{-1} \boldsymbol{K}+\boldsymbol{U}_{x}^{-1}\right)^{-1} \boldsymbol{K}^{T} \boldsymbol{S}_{\mathrm{d}, y}^{-1}\left(\boldsymbol{y}-\boldsymbol{y}_{0}\right)$,

where $\boldsymbol{y}$ is the measurement, $\boldsymbol{x}_{0}$ is a first guess of the unknown parameters and $\boldsymbol{y}_{0}$ is the associated simulated spectra, $\boldsymbol{K}=\frac{\partial \boldsymbol{T}_{\mathrm{b}}}{\partial \boldsymbol{x}}$ is the Jacobian matrix of the forward model (Eq. 1), $\boldsymbol{S}_{\mathrm{d}, y}$ is a diagonal matrix equal to the diagonal of $\boldsymbol{S}_{y}$ (Eq. 14) and $\boldsymbol{U}_{x}$ is a diagonal matrix for stabilizing the 
(a)

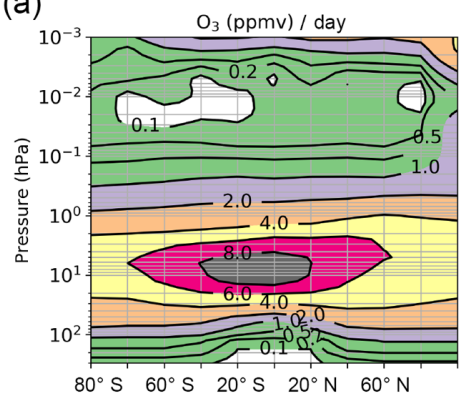

(b)

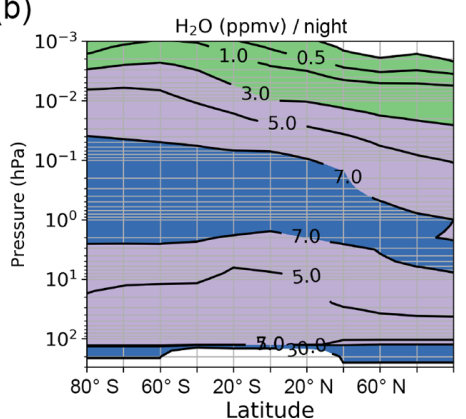

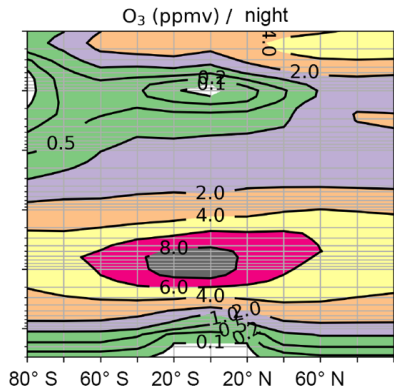

$80^{\circ} \mathrm{S} 60^{\circ} \mathrm{S} 20^{\circ} \mathrm{S} 20^{\circ} \mathrm{N} 60^{\circ} \mathrm{N}$

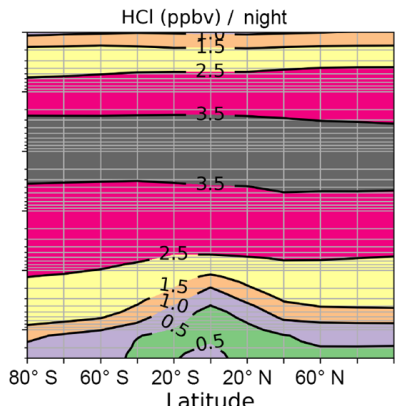

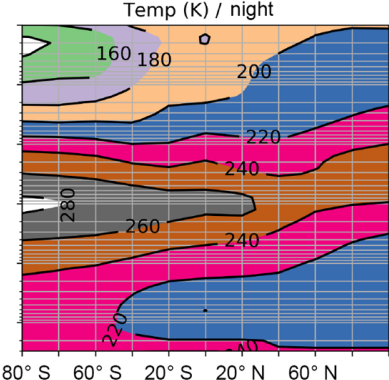

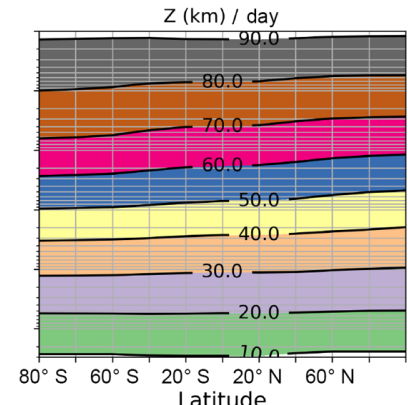

Figure 5. Zonal mean distribution of the most relevant atmospheric parameters for the retrieval error assessment. Images in (a) show the $\mathrm{O}_{3}$ distributions on pressure levels for day- and night-labeled climatologies as well as the night temperature one. Images in (b) show the night distributions for $\mathrm{H}_{2} \mathrm{O}, \mathrm{HCl}$ and geopotential altitude. The white regions indicate values smaller than the color scales.

(a)

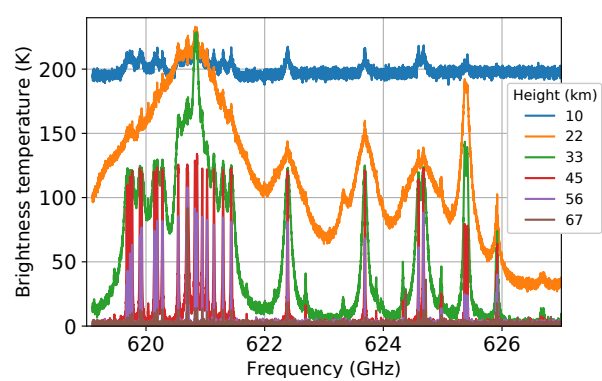

(b)

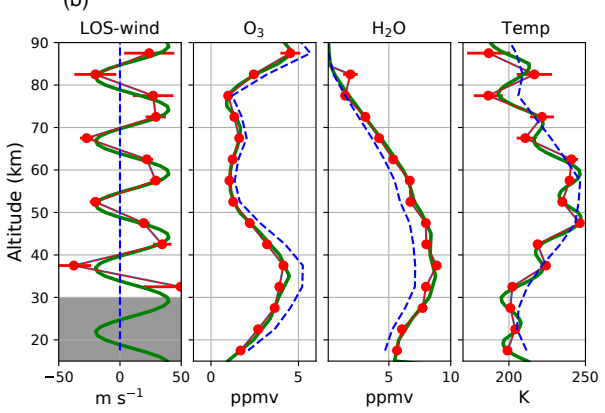

Figure 6. (a) Double sideband spectra with respect to the lower sideband frequency. Only a few spectra of the full vertical scan are shown (see legend). (b) Retrieved profiles with a vertical resolution of $5 \mathrm{~km}$ for nighttime arctic conditions. The blue-dashed lines are the a priori profiles (first guess), the green lines are the truth and the red line circles are the retrieved values. The horizontal bars indicate the $1 \sigma$ errors due to instrument thermal noise.

matrix inversion. Its element square roots correspond to very large standard deviations of $\boldsymbol{x}$, typically $>10000 \%, 1000 \mathrm{~K}$ and $1000 \mathrm{~ms}^{-1}$ for VMR, temperature and LOS wind, respectively. The regularization effects are negligible where the retrieval errors (null space and measurement errors) are much smaller than the $\boldsymbol{U}_{x}$-related STD. In other words, the averaging kernels are unity at altitudes where the measurement is relevant and the retrieval vertical resolution is that of the retrieval altitude grid.

The retrieval precision is derived from the linear mapping of the measurement noise covariance onto the retrieved pa- rameters space:

$\boldsymbol{\epsilon}_{x, \mathrm{n}}^{2}=\operatorname{diag}\left(\boldsymbol{G} \boldsymbol{S}_{y} \boldsymbol{G}^{T}\right)$,

where $\boldsymbol{\epsilon}_{x, \mathrm{n}}$ is the standard deviation of $\hat{\boldsymbol{x}}, \boldsymbol{S}_{y}$ is the full measurement covariance matrix (Eq. 14) and $\boldsymbol{G}=$ $\left(\boldsymbol{K}^{T} \boldsymbol{S}_{\mathrm{d}, y}^{-1} \boldsymbol{K}+\boldsymbol{U}_{x}^{-1}\right)^{-1} \boldsymbol{K}^{T} \boldsymbol{S}_{\mathrm{d}, y}^{-1}$.

Figure 6 (right panel) shows retrieved profiles of LOS wind, $\mathrm{O}_{3}, \mathrm{H}_{2} \mathrm{O}$ and temperature using a simulated noisy measurement (Fig. 6, left panel). The measurement is computed using perturbed profiles from the nighttime climatology at $80^{\circ} \mathrm{N}$, hereafter named true profiles. The true profiles are defined with a vertical resolution of $0.5 \mathrm{~km}$. The $\mathrm{H}_{2} \mathrm{O}$ and 
$\mathrm{HCl}$ climatological profiles are multiplied by 1.2 and the $\mathrm{O}_{3}$ one is multiplied by 0.8 . An offset of $-5 \mathrm{~K}\left(10 \mathrm{~m} \mathrm{~s}^{-1}\right)$ and a $9 \mathrm{~km}$ period oscillation with an amplitude of $8 \mathrm{~K}(15 \mathrm{~km}$, $30 \mathrm{~m} \mathrm{~s}^{-1}$ ) are added to the temperature (wind) profile. Good agreement is found between the retrieved and true profiles. Below $40 \mathrm{~km}$, the wind retrieval error strongly increases, and we should consider that $30 \mathrm{~km}$ is the lower altitude for wind retrieval. The error increase is due to the pressure broadening of the lines that is about $30-40 \mathrm{MHz}$ at $10 \mathrm{hPa}$. Other profiles are retrieved with low errors over most of the vertical range. A small oscillation is however seen in the $\mathrm{H}_{2} \mathrm{O}$ profile that likely arises from the simple retrieval calculation (linearity and weak regularization). These results are obtained with relatively large differences between the true and reference profiles and show that this retrieval setting can safely be used for the error analysis.

Systematic retrieval errors emerge from uncertainties in the instrument, calibration and forward model parameters and LOS angles (Table 2). It is difficult at this stage of the mission definition to provide proper values for these uncertainties. The given values are relatively close to those expected but rounded in a way that allows for straight-forward linear scaling of retrieval errors according to any future better knowledge of the parameter uncertainties. One may notice that the uncertainty in the line broadening parameter $\left(G_{i}\right)$ is likely underestimated and the actual values should be between 1 and $4 \%$ depending on the line. On the other hand, the calibration parameters are likely overestimated. Anyway these errors induce relatively constant retrieval biases that could be mitigated with ad hoc corrections if their properties are well understood, e.g., timescale and latitudinal variabilities (see for example the JEM/SMILES data analysis in Baron et al., 2013b).

The $24 \mathrm{~h}$ variability of the local oscillator frequency is between 2 and $10 \mathrm{kHz}$ which directly results in a LOS wind retrieval uncertainty of $1-5 \mathrm{~m} \mathrm{~s}^{-1}$. The lower limit corresponds to the scientific requirement and the upper one is the worse acceptable case. Though it is a systematic error, it changes from one scan to another one with a time correlation that has to be determined before launch. The impacts on other retrieved parameters are negligible. Given the proposed design of the instrument (Murtagh, 2016), the 1-year frequency variability may be relatively large ( $>0.5 \mathrm{MHz}$ or $\left.250 \mathrm{~m} \mathrm{~s}^{-1}\right)$, and we should consider that an absolute frequency knowledge, good enough for retrieving winds, may not be available. Frequency calibration will be performed using short-term wind retrieval bias estimates within 40-60 km where other systematic errors are small.

Retrieval errors from other parameters are investigated in Sect. 5.2 using a perturbation method:

$\boldsymbol{\epsilon}_{x, p}=\boldsymbol{G}\left(\boldsymbol{y}_{p}-\boldsymbol{y}_{0}\right)$,

where $\boldsymbol{\epsilon}_{x, p}$ is the error induced by the parameter $p$ and $\boldsymbol{y}_{p}$ is the measurement assessed after changing the value of $p$ according to its uncertainty. The spectroscopic errors are expressed for each molecule considering that the errors in the line parameters are mutually independent:

$\boldsymbol{\epsilon}_{x, \mathrm{M}}=\sqrt{\sum_{i}\left(\boldsymbol{\epsilon}_{x, \mathrm{M}, F_{i}}^{2}+\boldsymbol{\epsilon}_{x, \mathrm{M}, G_{i}}^{2}+\boldsymbol{\epsilon}_{x, \mathrm{M}, S_{i}}^{2}\right)}$,

where $\boldsymbol{\epsilon}_{x, \mathrm{M}}$ denotes the total spectroscopic error due the molecule $\mathrm{M}$, and $F_{i}, G_{i}$ and $S_{i}$ denote the center frequency, air-broadening parameter and line strength of the line $i$.

The following errors will not be discussed. The errors in the LOS azimuth and elevation angles induces error smaller than $1 \mathrm{~m} \mathrm{~s}^{-1}$ on the LOS wind retrievals. The mean elevation offset of the scan is retrieved with a precision better than $0.2 \mathrm{mrad}$. The retrieval error induced by the antenna efficiency is not discussed given that it has similar properties to that induced by the hot-load emission error (Eq. 12).

\section{Measurement performance}

\subsection{Retrieval precision}

Results are discussed on pressure levels and the corresponding altitudes are shown in Fig. 5. The precision $(1 \sigma)$ is given for a single scan and a vertical resolution of $5 \mathrm{~km}$. It is possible to use the altitude information inscribed in the pressure broadened lineshape for retrieving atmospheric profile at better resolution but at the cost of the precision. Precision degradation can be afforded for products retrieved from strong signals (e.g., $\mathrm{O}_{3}$ or temperature) or for those whose the vertical resolution is more scientifically relevant than the temporal or horizontal one (precision can be improved by averaging data). On the other hand, degrading the vertical resolution may be necessary for providing useful information on products derived from weak signals (e.g, $\mathrm{HOCl}$ ). Later, using the results of this study and based on scientific requirements, the retrieval algorithm will be optimized for providing the best compromise between precision and resolution for each of the main products. Let us note that for all products except for the LOS wind, there are two quasi-simultaneous and quasi-coincident retrievals available from the two LOS (Fig. 2). They can be averaged for improving the precision by a factor of $\sqrt{2}$.

\subsection{1 $\mathrm{O}_{3}$ retrieval}

Figure 7 shows the retrieval precisions for temperature, LOS wind, $\mathrm{O}_{3}$ and $\mathrm{H}_{2} \mathrm{O}$ that have the strongest lines. Good precision is found for $\mathrm{O}_{3}$ retrieval over the whole altitude range $(200-0.001 \mathrm{hPa})$ because of the unusually large number of lines compared to other MM/SMM instruments. Between 100 and $0.2 \mathrm{hPa}$, the relative error is better than $2 \%$ and does not vary significantly with latitude and local time. High precision of $<0.4 \%$ is found between 50 and $2 \mathrm{hPa}$. There, the retrieval vertical resolution could be improved to $3-4 \mathrm{~km}$ 
Table 2. Systematic errors in observational and forward model parameters: calibration hot-load temperature $\left(T_{\mathrm{h}}\right.$, Eq. 12) and radiance linearity assumption $(\alpha$, Eq. 11$)$, sideband ratio $\left(w_{1 \mathrm{lsb}}\right.$, Eq. 1$)$, local oscillator frequency $\left(v_{\mathrm{lo}}\right.$, Eq. 1$)$ over $24 \mathrm{~h}$ and 1 year, antenna efficiency $\left(\eta_{\mathrm{a}}\right.$, Eq. 8), spectroscopic line center frequency $(F)$, pressure broadening $(G)$ and strength $(S)$ and LOS azimuth and elevation angles $(\theta, \phi$, Fig. 4).

\begin{tabular}{cccccccccc}
\hline \multicolumn{2}{c}{ Calibration } & Sideband ratio & \multicolumn{2}{c}{ Local oscillator } & Ant. efficiency & \multicolumn{2}{c}{ Spectroscopy } & \multicolumn{2}{c}{ LOS angles } \\
$\epsilon T_{\mathrm{h}}$ & $\alpha$ & $w_{\text {lsb }}$ & $24 \mathrm{~h}$ & 1 year & $\eta_{\mathrm{a}}$ & $F$ & $G$ & $S$ & $\theta, \phi$ \\
\hline $1 \%$ & $0.5 \times 10^{-5}$ & $0.1 \%$ & $2-10 \mathrm{kHz}$ & $>0.5 \mathrm{MHz}$ & $\sim \epsilon T_{H}$ & $10 \mathrm{kHz}$ & $1 \%$ & $1 \%$ & $0.5 \mathrm{mrad}$ \\
\hline
\end{tabular}
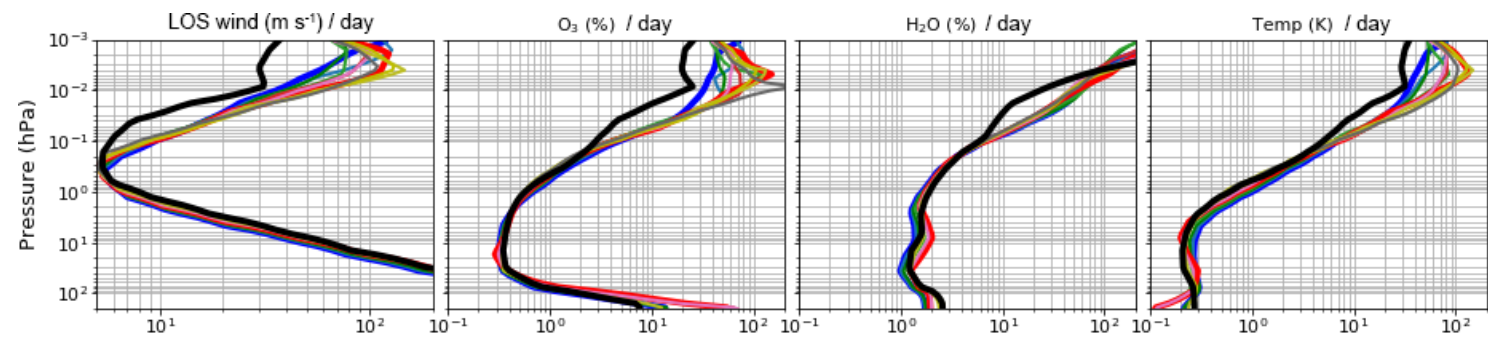

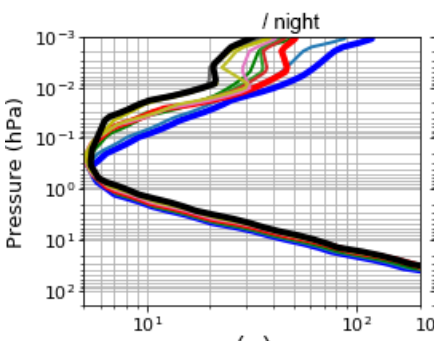

(a)

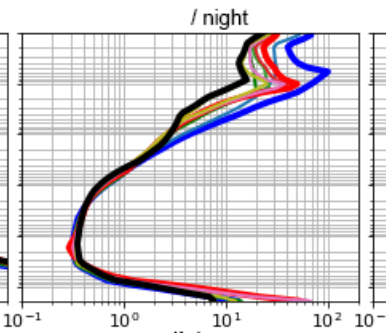

(b)

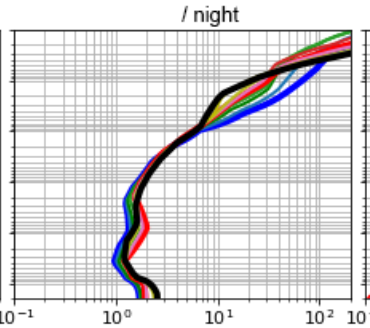

(c)

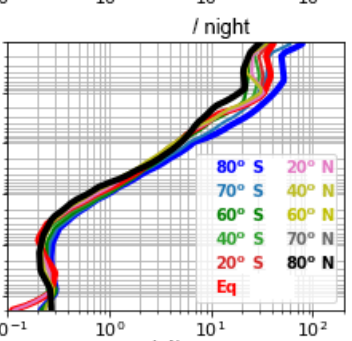

(d)

Figure 7. Single-scan retrieval precision $(1 \sigma)$ for line-of-sight wind (a), $\mathrm{O}_{3}(\mathbf{b}), \mathrm{H}_{2} \mathrm{O}(\mathbf{c})$ and temperature (d). The line colors correspond to latitude bins (see legend) and thick lines are used for those corresponding to polar and equatorial regions. Errors are given for day- and night-labeled profiles. Note that southern (northern) polar profiles are actually both daytime (nighttime) ones.

with a precision of $\approx 1 \%$ (not shown). In the upper part of the retrieval range, the relative precision strongly varies with latitude and local time. The errors are $30-50 \%$ in nighttime and $40-100 \%$ in daytime. The poorest relative precision is found near $0.01 \mathrm{hPa}$ during daytime, where most of $\mathrm{O}_{3}$ is photo-dissociated (Fig. 5). Above, the relative precision slightly improves due to the $\mathrm{O}_{3}$ mesospheric secondary peak (Fig. 5).

Figure 8 shows that above $1 \mathrm{hPa}$ most of $\mathrm{O}_{3}$ information is provided by the first half of the spectrum that contains the cluster of $\mathrm{O}_{3}$ lines near $655 \mathrm{GHz}$ (Figs. 3 and 6). Below this altitude, both sides of the spectrum contribute equally to the $\mathrm{O}_{3}$ retrieval. The $\mathrm{O}_{3}$ line cluster is the main source of information for the LOS wind and temperature retrievals above 4 and $200 \mathrm{hPa}$, respectively (Fig. 8).

\subsubsection{Wind and temperature retrievals}

The performance of the LOS wind retrieval strongly depends on the $\mathrm{O}_{3}$ abundance. With the current definition of the orbit (equatorial ascending node at 18:00 LT), most of the measurements are performed at nighttime (Fig. 2), which is a favorable time for measuring wind. The best performance is found over the northern polar region, where the nighttime $\mathrm{O}_{3}$ enhancement is the largest. There, the LOS wind can be retrieved with a precision better than $10 \mathrm{~m} \mathrm{~s}^{-1}$ between 2 and $0.02 \mathrm{hPa}$ (Fig. 7). Comparable performance is found for nighttime equatorial and mid-latitude retrievals over a similar vertical range but with a slightly lower upper limit (0.03-0.04 hPa). In daytime, the uppermost altitude for obtaining similar precision dropped to $0.1 \mathrm{hPa}$ over most of the latitudes. At $10 \mathrm{hPa}$, the error is $50-60 \mathrm{~m} \mathrm{~s}^{-1}$, and averaging 2 weeks of equatorial data in $10^{\circ}$ latitude bin gives a precision of about $2 \mathrm{~m} \mathrm{~s}^{-1}$. Since the precision is much poorer below this altitude, the $10 \mathrm{hPa}$ level should be considered as the lowest altitude for obtaining useful wind information.

At $0.01 \mathrm{hPa}$, the nighttime LOS wind precision changes with latitude from 20 to $50 \mathrm{~m} \mathrm{~s}^{-1}$ (the southern polar profile is excluded) and from 40 to $60 \mathrm{~m} \mathrm{~s}^{-1}$ in daytime. At this altitude, the $\mathrm{H}_{2} \mathrm{O}$ line at $620.7 \mathrm{GHz}$ contributes significantly to the wind retrieval, especially during daytime. Over the polar regions, strong NO enhancements frequently occur in the middle atmosphere due to energetic particle precipitation (EPP) (Randall et al., 2007; Pérot et al., 2014; Orsolini et al., 2017). During such events, the NO lines can be increased by 
(a)
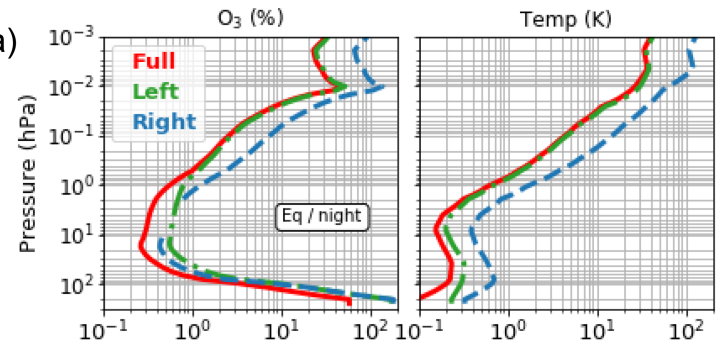

(b)

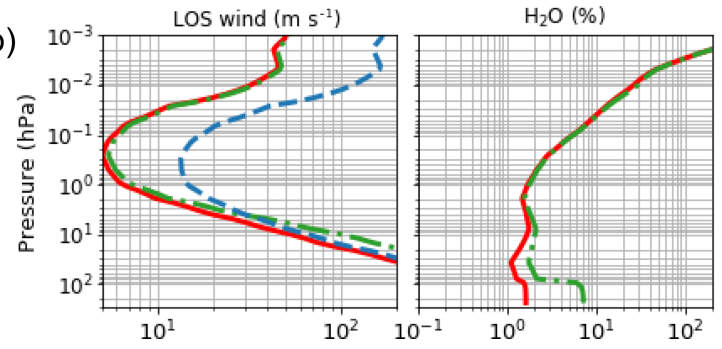

Figure 8. Single-scan retrieval precision $(1 \sigma)$ for $\mathrm{O}_{3}$ and temperature (a), and line-of-sight wind and $\mathrm{H}_{2} \mathrm{O}$ (b). Errors are calculated for a full band retrieval (red lines), the left half IF band (10.075-14.075 GHz, blue lines) and the right half IF band (14.075$18.075 \mathrm{GHz}$, green lines). Results are shown for equatorial nighttime conditions.

more than a factor of 10 , which would improve the wind and temperature retrievals.

Temperature can be retrieved with a precision better than $1 \mathrm{~K}$ below $1 \mathrm{hPa}$. The retrieval vertical resolution can be improved to $3 \mathrm{~km}$ with a precision better than $1 \mathrm{~K}$ between 200 and $5 \mathrm{hPa}$ (not shown). Above $0.2 \mathrm{hPa}$, the precision decreases to $10-30 \mathrm{~K}$ near $0.01 \mathrm{hPa}$ in nighttime and to $30-80 \mathrm{~K}$ in daytime. During daytime most of the mesospheric information is provided by the strong $\mathrm{H}_{2} \mathrm{O}$ line at $620.7 \mathrm{GHz}$.

\subsection{3 $\quad \mathrm{H}_{2} \mathrm{O}$ and other molecules retrievals}

The $\mathrm{H}_{2} \mathrm{O}$ profile is retrieved from the line at $620.7 \mathrm{GHz}$ and below $100 \mathrm{hPa}$, from the continuum induced by far lines. The precision is better than $3 \%(20 \%)$ below $0.3 \mathrm{hPa}(0.05 \mathrm{hPa})$. For altitudes above $0.1 \mathrm{hPa}$, the relative error increases and exhibits large latitudinal variations, e.g., $10-50 \%$ at $0.2 \mathrm{hPa}$. The largest errors are found during daytime when the signal from $\mathrm{O}_{3}$ is weak. Under such conditions, temperature is retrieved from the single $\mathrm{H}_{2} \mathrm{O}$ line. The forward model inversion becomes ill-conditioned and both $\mathrm{H}_{2} \mathrm{O}$ and temperature errors strongly increase. This issue is clearly illustrated with the much smaller $\mathrm{H}_{2} \mathrm{O}$ daytime errors estimated without retrieving temperature compared to those with temperature retrieval (Fig. 9). Constraining the mesospheric temperature would significantly improve the mesospheric $\mathrm{H}_{2} \mathrm{O}$ retrievals.

The retrieval precision for other molecules are shown in Fig. 9. First, we note that, except for $\mathrm{O}_{3}$ and $\mathrm{H}_{2} \mathrm{O}$, all chemical species are retrieved from optically thin lines and the VMR error profiles have similar characteristics and are in- dependent of the VMR values. The minimum VMR error is found near $10 \mathrm{hPa}$. Below, the errors increase due to spectral line overlapping. The atmosphere becomes opaque near the tropopause. From the middle stratosphere to the mesosphere, the errors increase due to the decrease of atmospheric density (the error is actually proportional to pressure ${ }^{-0.6}$ because the density decrease is partly compensated by the narrowing of the lines).

The best measurement performance with respect to the VMR is found for $\mathrm{HCl}, \mathrm{N}_{2} \mathrm{O}, \mathrm{HCN}, \mathrm{CH} 3 \mathrm{CN}$ and $\mathrm{HNO}_{3}$. Good information can also be inferred for the four most abundant $\mathrm{O}_{3}$ isotopologues and from HDO. Important chemically active species such as $\mathrm{ClO}, \mathrm{NO}, \mathrm{NO}_{2}$ or $\mathrm{HO}_{2}$ can also be retrieved. If necessary the relative precision can be improved by averaging profiles or decreasing the retrieval vertical resolution. Deriving useful information for species such as $\mathrm{BrO}$ or $\mathrm{HOCl}$ will be challenging.

Chemically active species exhibit large variabilities. The photo-chemistry-driven diurnal variation is the most common one. For instance, stratospheric $\mathrm{ClO}, \mathrm{NO}$ and mesospheric $\mathrm{HO}_{2}$ are more abundant in daytime but vanish in general during nighttime. Special events that occur more or less frequently can strongly increase the signal-to-noise ratio. For instance, $\mathrm{ClO}$ VMR frequently reaches $1.5 \mathrm{ppbv}$ near $20 \mathrm{~km}$ during polar springtime due to the chlorine activation during the polar winter. The enhancement of $\mathrm{SO}_{2}$ after strong volcanic eruption can also be measured (Pumphrey et al., 2015). EPP-induced enhancement of $\mathrm{NO}_{x}$ and $\mathrm{HO}_{x}$ is another example. During such events nighttime NO can reach levels of $10-100 \mathrm{ppbv}$ between 10 and $0.1 \mathrm{hPa}$, levels much larger than the measurement single-scan precision (2-20 ppbv). EPP-induced enhancements are not well represented in the models (Randall et al., 2007; Pérot et al., 2014; Orsolini et al., 2017), and SIW has strong potential to provide key insights into their dynamical and chemical sources.

\subsection{Systematic errors}

The errors induced by the spectroscopic uncertainties in the most important lines have been estimated for the LOS wind, temperature, $\mathrm{O}_{3}, \mathrm{H}_{2} \mathrm{O}$ and $\mathrm{HCl}$ retrievals. We consider the 50 most intense $\mathrm{O}_{3}$ lines over the whole bandwidth, two $\mathrm{HCl}$ triplets $(624.9$ and $625.9 \mathrm{GHz})$, two NO triplets $(651.4$ and

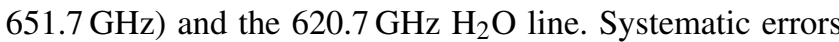
induced by the double-sideband ratio (DSB), the calibration hot-load temperature and the radiometer non-linearity are also discussed for the same products.

\subsubsection{Wind retrieval}

Figure 10 clearly shows three altitude ranges for the wind retrieval errors induced by the spectroscopic parameters. Results are given for the latitude $60^{\circ} \mathrm{N}$. Above $0.1 \mathrm{hPa}$, a daytime error of $3-5 \mathrm{~m} \mathrm{~s}^{-1}$ is induced by the frequency uncertainty in the $\mathrm{H}_{2} \mathrm{O}$ line (Table A3). During nighttime, the sig- 

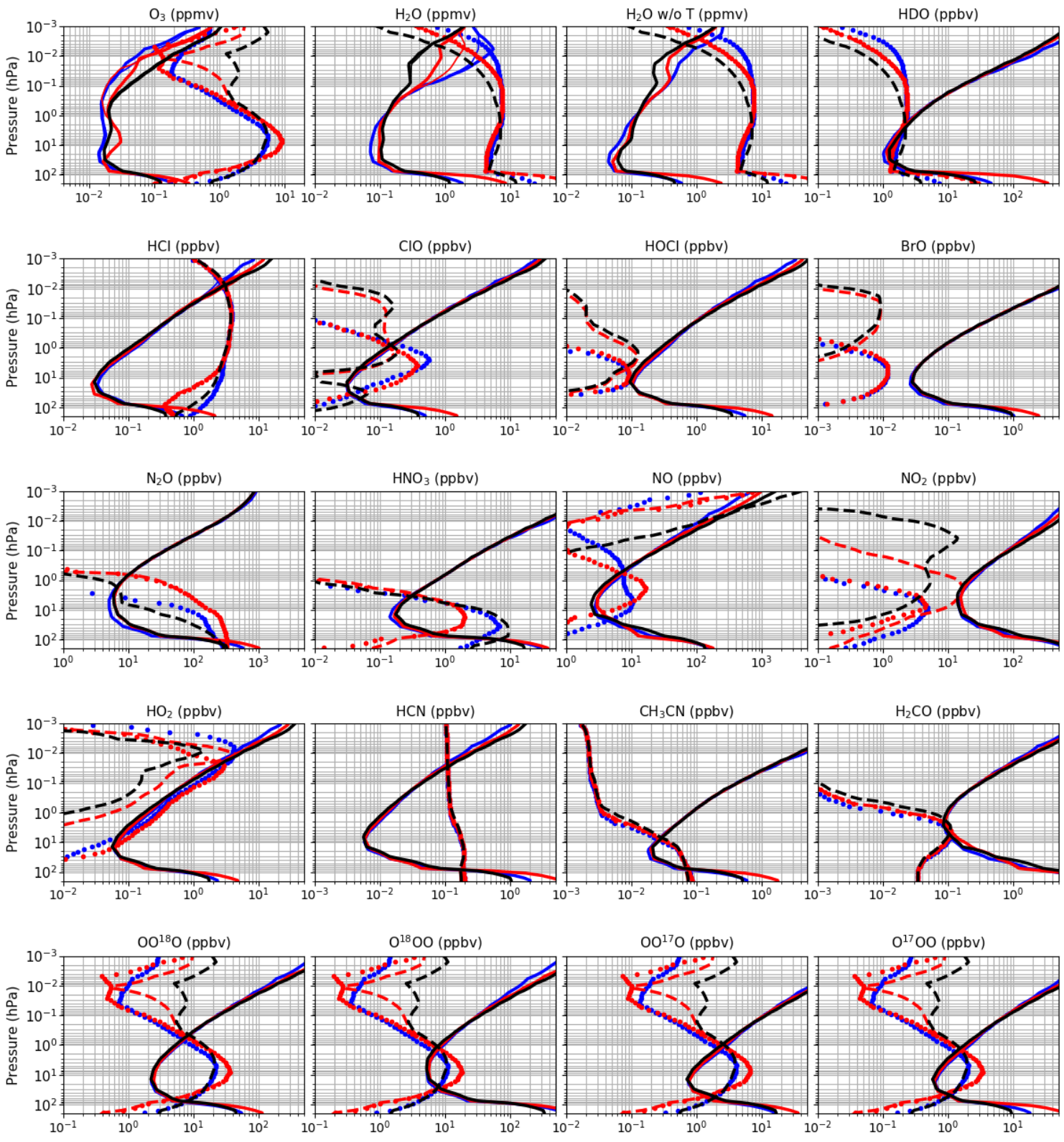

Figure 9. Single-scan retrieval precision (full lines), nighttime VMR (dashed lines) and daytime VMR (dotted lines) profiles. Profiles are shown at $80^{\circ} \mathrm{S}$ (blue line), Equator (red line) and $80^{\circ} \mathrm{N}$ (black line). The thick (thin) red full lines are nighttime (daytime) conditions. The $\mathrm{H}_{2} \mathrm{O}$ results without temperature retrieval are indicated by "w/o T".

nal is dominated by about $15 \mathrm{O}_{3}$ lines and a retrieval error of only $1 \mathrm{~m} \mathrm{~s}^{-1}$ is induced by their frequency uncertainty (Tables A1 and A2). The same error of $1 \mathrm{~m} \mathrm{~s}^{-1}$ is found between 1 and $0.1 \mathrm{hPa}$ both during day and nighttime. No impact of the NO lines has been found, even at higher latitudes, but this is not be the case for EPP-enhanced profiles. Below $1 \mathrm{hPa}$, the lines broadened by the pressure overlap each other. Consequently the uncertainties in the air-broadening parameters and to a lesser extent, the line strength of the $\mathrm{O}_{3}$ lines contribute to the retrieval error. The bias increases up to 20 $30 \mathrm{~m} \mathrm{~s}^{-1}$ at $10 \mathrm{hPa}$.
Figure 11 shows the retrieval errors induced by the doublesideband ratio (DSB), the calibration hot-load temperature and the radiometer non-linearity. These parameters introduce errors in the wind retrieval only below $1 \mathrm{hPa}$. The uncertainty in the calibration hot-load temperature is the dominant retrieval error, reaching 5-8 $\mathrm{m} \mathrm{s}^{-1}$ between 2 and $10 \mathrm{hPa}$. Overall, the $\mathrm{O}_{3}$ lines parameters are the main source of error between 10 and $1 \mathrm{hPa}$ for all latitudes (Fig. 12).

Methods for mitigating wind retrieval bias have to be developed taking into account SIW observation characteristics (see Appendix A). For JEM/SMILES analysis, a retrieval 

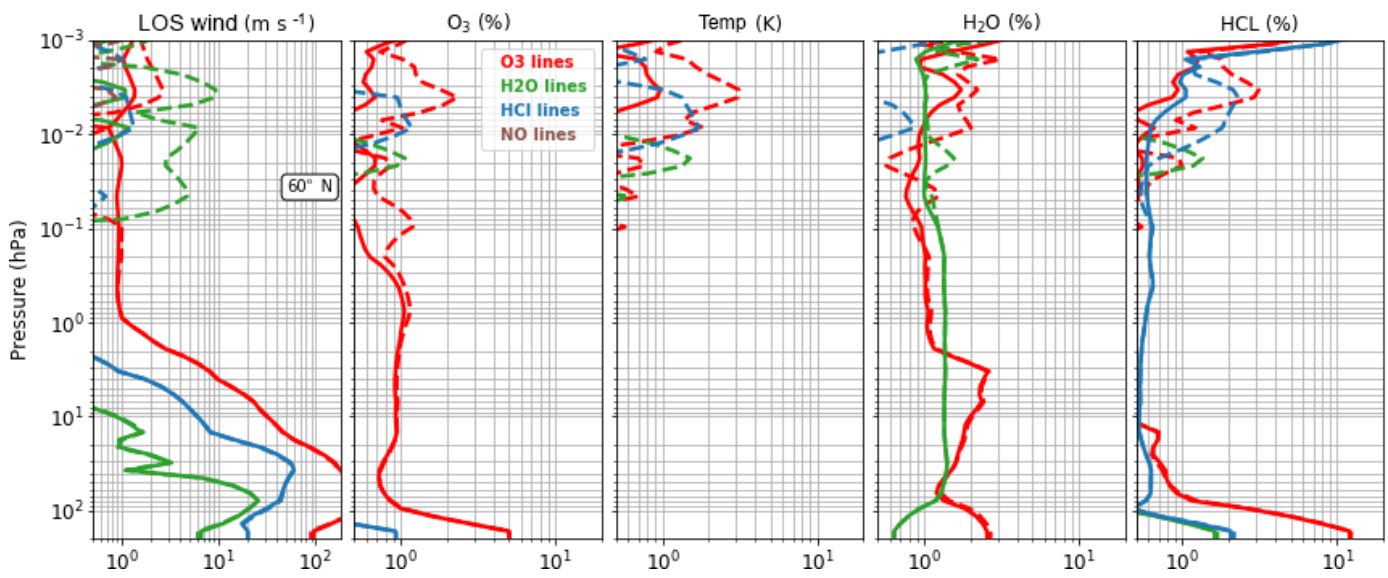

Figure 10. Spectroscopic-induced errors in LOS wind, temperature, $\mathrm{O}_{3}, \mathrm{H}_{2} \mathrm{O}$ and $\mathrm{HCl}$ retrievals (see panel titles). The full lines (dashed lines) show the nighttime (daytime) conditions at $60^{\circ} \mathrm{N}$.
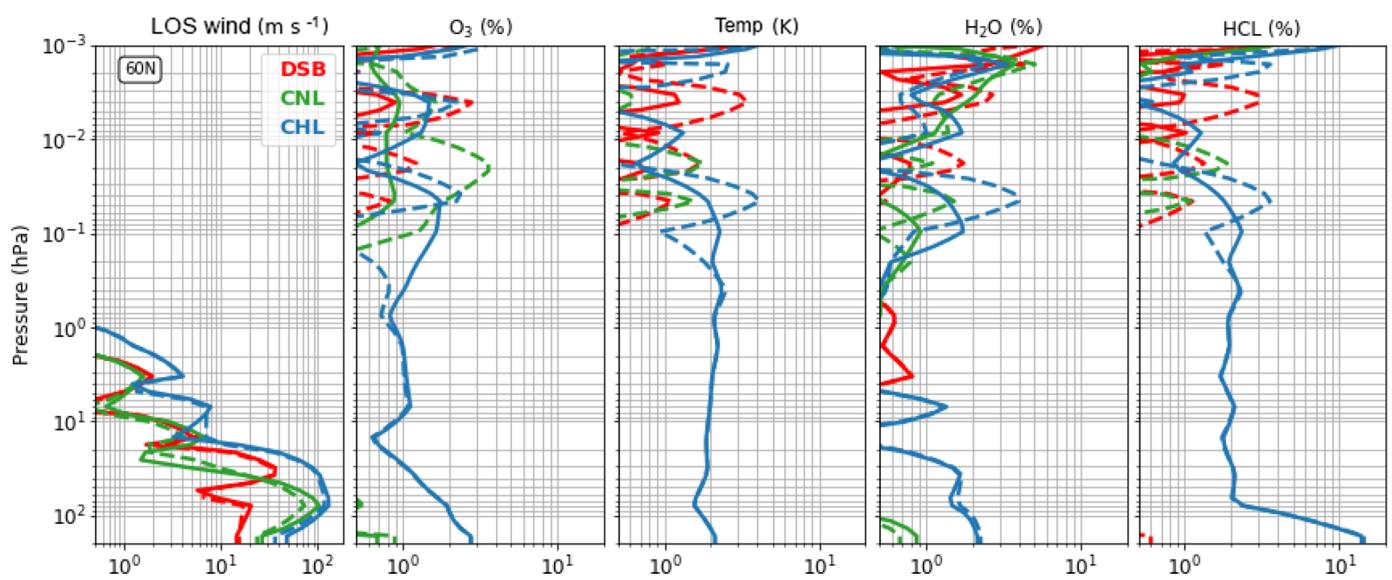

Figure 11. Same as Fig. 10 but for double-sideband ratio (DSB), radiometer nonlinearity (CNL) and calibration hot-load emission (CHL). The error assumptions are summarized in Table 2.

bias of $20-40 \mathrm{~m} \mathrm{~s}^{-1}$ between 8 and $5 \mathrm{hPa}$ was reduced to less than $4 \mathrm{~m} \mathrm{~s}^{-1}$ between $30^{\circ} \mathrm{S}$ and $50^{\circ} \mathrm{N}$ by considering that the mean tropical flow is zonal (Baron et al., 2013b). Meteorological analysis and reanalysis at mid-latitudes can also be used for characterizing the retrieval biases below $5 \mathrm{hPa}$.

\subsubsection{Temperature and VMR retrievals}

The biases of $\mathrm{O}_{3}, \mathrm{HCl}$ and temperature retrievals due to the spectroscopic parameters are small. They are lower than $1 \%$ and $0.5 \mathrm{~K}$ between 100 and $0.02 \mathrm{hPa}$. Above $0.02 \mathrm{hPa}$, the biases increase but remain smaller than $5 \%$ and $4 \mathrm{~K}$. The errors are induced by the air-broadening and strength parameters of $\mathrm{O}_{3}$ and $\mathrm{H}_{2} \mathrm{O}$ lines. The strong impact of the $\mathrm{H}_{2} \mathrm{O}$ line parameters onto the $\mathrm{HCl}$ retrieval reveals error amplifications due to the temperature retrieval. Using constraints on the temperature retrieval should allow us to reduce such effects.

The retrieval of $\mathrm{H}_{2} \mathrm{O}$ above $0.2 \mathrm{hPa}$ has a small bias $<2 \%$ that is induced by the uncertainties in the air-broadening and

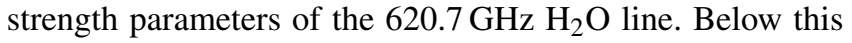
altitude, the retrieval error reaches $5 \%$ mainly due to the airbroadening parameters of the overlapping $\mathrm{O}_{3}$ lines at 620.69 and $623.669 \mathrm{GHz}$ (Table A1). Below $100 \mathrm{hPa}$, the $\mathrm{H}_{2} \mathrm{O}$ lines outside the band are the main signal for the retrieval (not

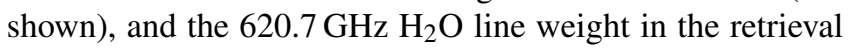
is small.

The DSB- and calibration-parameter-induced errors in $\mathrm{O}_{3}$, $\mathrm{HCl}$ and temperature retrievals are small below $0.1 \mathrm{hPa}$, i.e., lower than $3 \%$ and $2 \mathrm{~K}$ (Fig. 11). The calibration hot-load temperature and the radiometer non-linearity dominate the temperature retrieval error. The VMR and temperature retrievals are also sensitive to the DSB uncertainties and radiometer non-linearity above $0.1 \mathrm{hPa}$, especially in daytime. The daytime errors are likely increased by the temperature retrieval. 
(a)
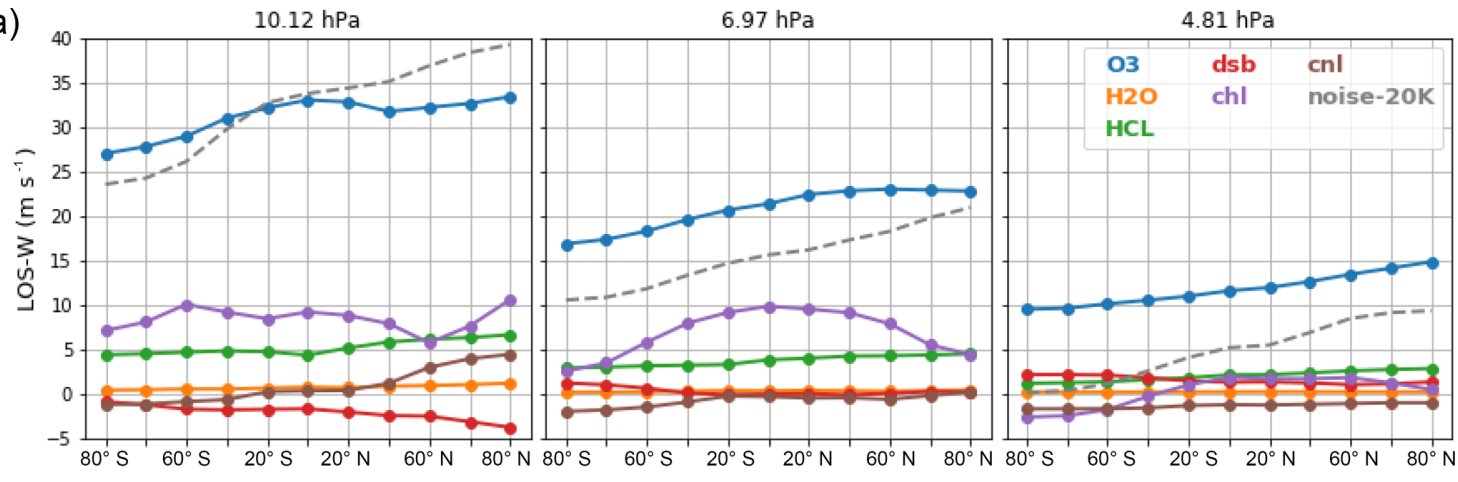

(b)
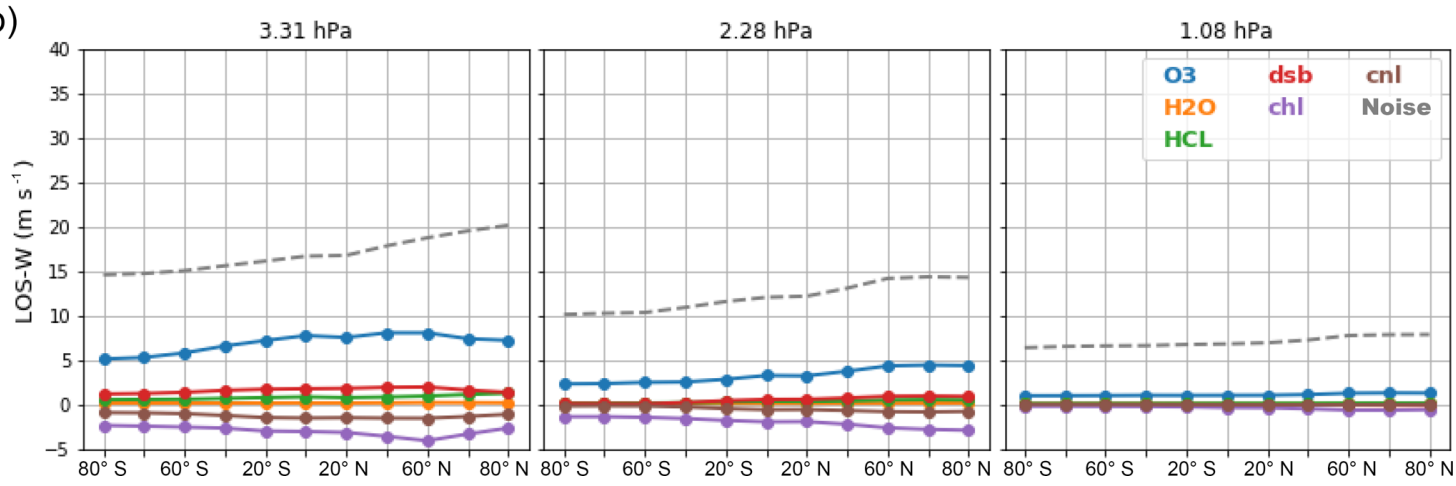

Figure 12. Line-of-sight wind retrieval biases with respect to latitudes near 10, 7 and $5 \mathrm{hPa}$ (a), and near 3,2 and $1 \mathrm{hPa}$ (b). Biases are shown for the uncertainties in the spectroscopic parameters of $\mathrm{O}_{3}, \mathrm{HCl}$, and $\mathrm{H}_{2} \mathrm{O}$, the double-sideband ratio, the calibration hot load and the calibration non-linearity.

\section{Conclusions}

A simulation study has been conducted to support the mission definition of SIW and to assess the measurement performance. This small instrument will be launched around 2022 in order to monitor the middle atmosphere (10-90 km) using the thermal emission lines near $640 \mathrm{GHz}$ of a large number of chemical species. This analysis focuses on the main outcomes, namely LOS wind, temperature, $\mathrm{O}_{3}$ and more than a dozen of other chemical species. The error assessment is performed taking into account the day-night and latitudinal atmospheric variabilities.

The unusually large number of strong $\mathrm{O}_{3}$ lines at 653$657 \mathrm{GHz}$ allows us to measure the 2-D horizontal wind between 10 and $0.001 \mathrm{hPa}$ and temperature between 100 and $0.1 \mathrm{hPa}$ as well as providing high sensitivity to $\mathrm{O}_{3}$ between 100 and $0.001 \mathrm{hPa}$. It is the first time such a mission is designed for measuring horizontal winds. These measurements demand a special observation setting involving two antennas in order to retrieve two perpendicular components of the wind vector. Each component can be measured between 2 and $0.03 \mathrm{hPa}$ with precision better than $10 \mathrm{~m} \mathrm{~s}^{-1}$ and vertical resolution of $5 \mathrm{~km}$. Other spaceborne instruments have poor sensitivity in this altitude range. A sun-synchronous polar orbit allowing us to perform nighttime measurements is currently being considered. Such conditions are most favorable for mesospheric wind, temperature and ozone measurements but not for active chemical species such as stratospheric $\mathrm{ClO}$ or strato-mesospheric $\mathrm{HO}_{2}$ that generally vanish during nighttime.

The impact of systematic errors induced by the spectroscopic parameters and by the instrument and calibration parameters are discussed. This work highlights the need for good characterization of the spectroscopic parameters (air broadening, strength, center frequency and pressure shift) of key $\mathrm{O}_{3}, \mathrm{H}_{2} \mathrm{O}$ and $\mathrm{NO}$ lines. Even so, a large wind measurement bias may occur between 10 and $2 \mathrm{hPa}$ mainly due to errors in $\mathrm{O}_{3}$ line air-broadening parameters. Hence ad hoc methods for reducing retrieval biases must be studied. These methods can be used to calibrate the long-term LO frequency trend that may arise with the proposed hardware. However, improvements of the instrument design for following the LO frequency with a precision better than $2 \mathrm{kHz}$ are still being investigated.

SIW shows strong potential for the study of various scientific questions. It can provide for the first time global information on the horizontal wind between 30 and $90 \mathrm{~km}$ that can be used to validate chemical and climate models. It has the potential to contribute to the characterization of long trend series of temperature, $\mathrm{O}_{3}, \mathrm{H}_{2} \mathrm{O}$ and $\mathrm{HCl}$, which are important 
for climate studies and for monitoring the chemical composition of the middle atmosphere. The mission can provide data to study the dynamics of the middle atmosphere. Based on SIW observations, it will be possible to carry out specific studies on key dynamical processes, such as the quasibiennial oscillation, the semi-annual oscillation or sudden stratospheric events for example. A better understanding of these phenomena, in addition to global middle-atmospheric wind measurements, would significantly improve our knowledge of the climate system. Not discussed in this paper is the capability of SIW for measuring ice water content in the tropical upper troposphere (Eriksson et al., 2014). Observing the same air mass from two perpendicular directions could provide interesting information considering the high spatial inhomogeneities of cloudy conditions.

Optimization of the calibration procedure will be studied in order to improve the measurement precision. Here we have assumed an equal observation time for the cold-sky and atmosphere measurements. Changing the time allotment in favor of atmospheric observations could improve measurement sensitivity by more than $20 \%$. The retrievals could also be improved in the mesosphere by increasing the frequency resolution to $0.5 \mathrm{MHz}$ at the intermediate frequency range between 17.2 and $17.4 \mathrm{GHz}$ that contains the strong $\mathrm{H}_{2} \mathrm{O}$ line $(620.701 \mathrm{GHz})$ and the two strongest $\mathrm{O}_{3}$ lines $(620.825$ and $655.289 \mathrm{GHz}$ ). Implementing such a setting is under investigation.
The InnoSat platform offers a rapidly approaching opportunity to fly SIW. This is important since current SMM limb instruments have already by far exceeded their expected lifetimes and are at risk of stopping operation in the near future. However such a platform strongly limits the design of an SMM instrument and its performance. A larger antenna would improve the vertical resolution and an additional receiver with narrow bandwidth measuring an oxygen or a strong water vapor line would significantly improve the wind and temperature retrievals in the mesosphere. Such improvements are being considered for the much larger SMILES-2 instrument (Ochiai et al., 2017) presented in the introduction section and which also includes the same spectral window as SIW. However this instrument cannot be launched before 2025 if decided upon.

Data availability. Model and data are available upon request . 


\section{Appendix A: LOS and horizontal winds}

The retrieval of two line-of-sight winds over the same region allows us to compute the meridional $(V)$ and zonal $(U)$ components of the horizontal wind vector. Applying Eq. (6) to the forward and aftward viewing antenna, the two retrieved LOS winds are

$$
\begin{aligned}
V_{\text {los,fwd }} & =U \sin \left(\phi_{\mathrm{n}}\right)+V \cos \left(\phi_{\mathrm{n}}\right), \\
V_{\mathrm{los}, \mathrm{aft}} & =U \sin \left(\phi_{\mathrm{n}}+\delta\right)+V \cos \left(\phi_{\mathrm{n}}+\delta\right),
\end{aligned}
$$

where $\phi_{\mathrm{n}}$ is the angle of the forward-looking line of sight with respect to the north direction and $\delta$ is the angle between the two lines of sight. It is straight forward to show that

$$
\begin{aligned}
& U=\frac{1}{\sin (\delta)}\left(V_{\text {los, aft }} \cos \left(\phi_{\mathrm{n}}\right)-V_{\text {los,fwd }} \cos \left(\phi_{\mathrm{n}}+\delta\right)\right), \\
& V=\frac{1}{\sin (\delta)}\left(V_{\text {los,fwd }} \sin \left(\phi_{\mathrm{n}}+\delta\right)-V_{\text {los, aft }} \sin \left(\phi_{\mathrm{n}}\right)\right),
\end{aligned}
$$

and the random errors in $U$ and $V$ are

$\epsilon_{U}=\frac{\epsilon_{\mathrm{los}}}{\sin (\delta)} \sqrt{\cos \left(\phi_{\mathrm{n}}+\delta\right)^{2}+\cos \left(\phi_{\mathrm{n}}\right)^{2}}$,

$\epsilon_{V}=\frac{\epsilon_{\mathrm{los}}}{\sin (\delta)} \sqrt{\sin \left(\phi_{\mathrm{n}}+\delta\right)^{2}+\sin \left(\phi_{\mathrm{n}}\right)^{2}}$,

where $\epsilon_{\text {los }}$ is line-of-sight wind retrieval error.

For $\delta=90^{\circ}$, we have

$U=\left(V_{\text {los, aft }} \cos \left(\phi_{\mathrm{n}}\right)+V_{\text {los,fwd }} \sin \left(\phi_{\mathrm{n}}\right)\right)$,

$V=\left(V_{\text {los, fwd }} \cos \left(\phi_{\mathrm{n}}\right)-V_{\text {losaft }} \sin \left(\phi_{\mathrm{n}}\right)\right)$.

The random error in each wind component becomes $\epsilon_{U}=$ $\epsilon_{V}=\epsilon_{\text {los }}$. This configuration is that for which $\epsilon_{U}^{2}+\epsilon_{V}^{2}=$ $2\left(\epsilon_{\operatorname{los}} / \sin (\delta)\right)^{2}$ is minimum.

A systematic error $e_{\text {los }}$ on the LOS wind retrievals propagates to the $U$ and $V$ components as follows:

1. the systematic error in the zonal wind estimate is $e_{u}=$ $e_{\operatorname{los}}\left(\cos \left(\phi_{\mathrm{n}}\right)+\sin \left(\phi_{\mathrm{n}}\right)\right)$;

2. the systematic error in the meridional wind estimate is $e_{v}=e_{\mathrm{los}}\left(\cos \left(\phi_{\mathrm{n}}\right)-\sin \left(\phi_{\mathrm{n}}\right)\right)$.

We assume that $e_{\text {los }}$ does not depends on the LOS orientation which is a valid assumption for the errors investigated in this paper (LO frequency, calibration, spectroscopy). We should note that $e_{v}=0$ for $\phi_{\mathrm{n}}=45^{\circ}$ or $225^{\circ}$, which occurs at latitudes between 30 and $50^{\circ} \mathrm{N}$ on the ascending branch of the orbit and between 10 and $30^{\circ} \mathrm{N}$ on the descending branch. The cases $e_{u}=0$ occur for the measurements from the orbit positions with the lowest and highest latitudes.
At the Equator, the bias of the meridional wind is partly canceled out. For instance, an error $e_{\mathrm{los}}=1.0 \mathrm{~m} \mathrm{~s}^{-1}$ induces an error $e_{v}=0.2 \mathrm{~m} \mathrm{~s}^{-1}$. Hence, using the tropical zonal wind to characterize the measurement bias as it was done in the JEM/SMILES analysis may not be a satisfactory method for SIW. On the other hand, $e_{\text {los }}=1.0 \mathrm{~m} \mathrm{~s}^{-1}$ leads to an error $e_{u}=1.4 \mathrm{~m} \mathrm{~s}^{-1}$ on the zonal component with an opposite sign on the ascending and descending orbit branches. The sign difference may provide us with a way to characterize LOS wind retrieval systematic errors.

\section{Appendix B: Spectroscopic lines}

The following tables show the most relevant spectroscopic lines for the retrievals of the LOS wind, $\mathrm{O}_{3}$, temperature, $\mathrm{H}_{2} \mathrm{O}$ and $\mathrm{HCl}$. The relative retrieval impact of each parameter is defined as

$$
\varrho_{x, M, p_{i}}=\frac{\boldsymbol{\epsilon}_{x, M, p_{i}}}{\max \left(\left\{\boldsymbol{\epsilon}_{x, M, p_{i}}\right\}_{p, i}\right)} \text { with } p_{i}=F_{i}, G_{i} \text { or } S_{i},
$$

where $M$ denotes the chemical species, $\boldsymbol{\epsilon}_{x, M, p_{i}}$ is the error induced by the parameter $p$ of the line $i$ (Eq. 18) and $\left\{\boldsymbol{\epsilon}_{x, M, p_{i}}\right\}_{p, i}$ is the set of errors induced by all the parameters of all the lines of the species $M$. 
Table A1. Relative impact of $\mathrm{O}_{3}$ line parameters on temperature, $\mathrm{O}_{3}, \mathrm{H}_{2} \mathrm{O}$ and LOS wind retrievals. For a retrieved product, the impact is defined as the ratio of the error to the maximum error (see text). Results are given for 10,1 and $0.1 \mathrm{hPa}$ levels (equatorial nighttime conditions). Only parameters having an impact larger than 0.5 at any of the considered altitudes are shown. The parameters are the center frequency $(S)$, the air-broadening parameter $(G)$ and the line strength $(S)$. The line is characterized by its frequency $(\mathrm{MHz})$.

\begin{tabular}{|c|c|c|c|c|c|c|c|c|c|c|c|c|c|c|c|}
\hline \multirow{2}{*}{ Parameter } & \multicolumn{3}{|c|}{ LOS wind } & \multicolumn{3}{|c|}{$\mathrm{O}_{3}$} & \multicolumn{3}{|c|}{ Temperature } & \multicolumn{3}{|c|}{$\mathrm{H}_{2} \mathrm{O}$} & \multicolumn{3}{|c|}{$\mathrm{HCl}$} \\
\hline & \multicolumn{15}{|c|}{ lower sideband } \\
\hline $620687-F$ & - & - & 0.6 & - & - & - & - & - & - & - & - & - & - & - & - \\
\hline$-G$ & - & -0.5 & - & - & - & - & - & - & - & 0.8 & 0.5 & - & - & - & - \\
\hline$-S$ & - & -1.0 & - & - & - & - & - & - & -0.5 & 1.0 & 0.7 & - & - & - & - \\
\hline $620825-F$ & - & 0.6 & 1.0 & - & - & - & - & - & - & - & - & - & - & - & - \\
\hline$-G$ & 0.8 & - & - & - & - & - & - & 0.9 & - & 0.7 & - & - & - & - & - \\
\hline$-S$ & 0.7 & - & - & - & - & - & - & 1.0 & 0.8 & 0.6 & - & - & - & - & - \\
\hline $623688-F$ & - & 0.8 & 0.7 & - & - & - & - & - & - & - & - & - & - & - & - \\
\hline$-G$ & - & - & - & - & - & - & 0.8 & - & - & -0.7 & -0.5 & - & - & - & - \\
\hline$-S$ & - & - & - & - & - & - & 1.0 & - & - & -0.8 & -0.5 & - & - & - & - \\
\hline $625370-F$ & - & 0.7 & - & - & - & - & - & - & - & - & - & - & - & - & - \\
\hline$-G$ & -1.0 & - & - & - & - & - & - & - & - & - & - & - & - & - & - \\
\hline \multirow[t]{2}{*}{$-S$} & - & - & - & 1.0 & 1.0 & 1.0 & -1.0 & - & 0.5 & - & 1.0 & 1.0 & - & 1.0 & 1.0 \\
\hline & \multicolumn{15}{|c|}{ upper sideband } \\
\hline $650732-F$ & - & 0.7 & - & - & - & - & - & - & - & - & - & - & - & - & - \\
\hline$-G$ & -1.0 & - & - & - & - & - & - & - & - & - & - & - & - & - & - \\
\hline$-S$ & -0.5 & - & - & 0.9 & 0.9 & 0.9 & -0.9 & - & - & - & 0.9 & 0.9 & - & 1.0 & 0.9 \\
\hline $651475-F$ & - & 0.7 & 1.0 & - & - & - & - & - & - & - & - & - & - & - & - \\
\hline$-G$ & -0.5 & - & - & - & - & - & - & - & - & - & - & - & 1.0 & - & - \\
\hline$-S$ & -0.6 & - & - & - & - & - & - & - & - & -0.5 & - & - & 1.0 & - & - \\
\hline $651556-F$ & - & 0.9 & 0.5 & - & - & - & - & - & - & - & - & - & - & - & - \\
\hline$-S$ & - & - & - & - & - & - & - & - & -0.9 & - & - & - & - & - & - \\
\hline $653763-F$ & - & 0.7 & 0.9 & - & - & - & - & - & - & - & - & - & - & - & - \\
\hline$-G$ & - & - & - & - & - & - & - & - & - & - & - & - & -0.6 & - & - \\
\hline$-S$ & - & - & - & - & - & - & - & - & - & - & - & - & -0.6 & - & - \\
\hline
\end{tabular}


Table A2. Continuation of Table A1.

\begin{tabular}{|c|c|c|c|c|c|c|c|c|c|c|c|c|c|c|c|}
\hline \multirow{2}{*}{$\begin{array}{l}\text { Parameter } \\
654713-F\end{array}$} & \multicolumn{3}{|c|}{ LOS wind } & \multicolumn{3}{|c|}{$\mathrm{O}_{3}$} & \multicolumn{3}{|c|}{ Temperature } & \multicolumn{3}{|c|}{$\mathrm{H}_{2} \mathrm{O}$} & \multicolumn{3}{|c|}{$\mathrm{HCl}$} \\
\hline & - & 0.7 & 0.9 & - & - & - & - & - & - & - & - & - & - & - & - \\
\hline$-S$ & -0.5 & - & - & - & - & - & - & - & - & - & - & - & - & - & - \\
\hline $654851-F$ & - & 0.7 & 0.9 & - & - & - & - & - & - & - & - & - & - & - & - \\
\hline $655004-F$ & - & 0.7 & 0.8 & - & - & - & - & - & - & - & - & - & - & - & - \\
\hline $655121-F$ & - & 0.7 & 0.8 & - & - & - & - & - & - & - & - & - & - & - & - \\
\hline $655202-F$ & - & 0.7 & 0.9 & - & - & - & - & - & - & - & - & - & - & - & - \\
\hline $655289-F$ & - & 0.6 & 1.0 & - & - & - & - & - & - & - & - & - & - & - & - \\
\hline$-G$ & - & - & - & - & - & - & - & 0.5 & - & - & - & - & - & - & - \\
\hline$-S$ & - & - & - & - & - & - & - & 0.6 & 0.8 & - & - & - & - & - & - \\
\hline $655607-F$ & - & 0.7 & 0.9 & - & - & - & - & - & - & - & - & - & - & - & - \\
\hline$-S$ & - & - & - & - & - & - & - & - & - & - & 0.5 & - & - & - & - \\
\hline $655873-F$ & - & 0.7 & 0.9 & - & - & - & - & - & - & - & - & - & - & - & - \\
\hline $655960-F$ & - & 0.7 & 0.9 & - & - & - & - & - & - & - & - & - & - & - & - \\
\hline $656005-F$ & - & 0.8 & 0.8 & - & - & - & - & - & - & - & - & - & - & - & - \\
\hline$-S$ & - & - & - & - & - & - & - & - & 0.5 & - & - & - & - & - & - \\
\hline $656224-F$ & - & 0.7 & 0.8 & - & - & - & - & - & - & - & - & - & - & - & - \\
\hline $656251-F$ & - & 0.7 & 0.7 & - & - & - & - & - & - & - & - & - & - & - & - \\
\hline $656383-F$ & - & 0.8 & 0.6 & - & - & - & - & - & - & - & - & - & - & - & - \\
\hline$-S$ & - & - & - & - & - & - & - & - & -0.6 & - & - & - & - & - & - \\
\hline $656419-F$ & - & 0.8 & 0.5 & - & - & - & - & - & - & - & - & - & - & - & - \\
\hline$-S$ & - & - & - & - & - & - & - & - & -0.9 & - & - & - & - & - & - \\
\hline $656461-F$ & - & 0.7 & - & - & - & - & - & - & - & - & - & - & - & - & - \\
\hline$-S$ & - & - & - & - & - & - & - & - & -1.0 & - & - & - & - & - & - \\
\hline $656476-F$ & - & 0.6 & - & - & - & - & - & - & - & - & - & - & - & - & - \\
\hline$-S$ & - & - & - & - & - & - & - & - & -0.7 & - & - & - & - & - & - \\
\hline
\end{tabular}

Table A3. Same as Table A1 but for the $\mathrm{H}_{2} \mathrm{O}$ line parameters

\begin{tabular}{lrrr|rrr|rr|rr|rr|rrr}
\hline Parameter & \multicolumn{3}{c}{ LOS wind } & \multicolumn{3}{c}{$\mathrm{O}_{3}$} & \multicolumn{2}{c}{ Temperature } & \multicolumn{3}{c}{$\mathrm{H}_{2} \mathrm{O}$} & \multicolumn{3}{c}{$\mathrm{HCl}$} \\
\hline $620701-F$ & - & $\mathbf{1 . 0}$ & $\mathbf{1 . 0}$ & - & $-\mathbf{1 . 0}$ & - & - & - & - & - & - & - & - & 0.5 & - \\
$-G$ & $\mathbf{1 . 0}$ & $-\mathbf{1 . 0}$ & - & 0.9 & 0.8 & $\mathbf{1 . 0}$ & 0.6 & - & $\mathbf{1 . 0}$ & 0.9 & 0.9 & 0.7 & 0.7 & - & $\mathbf{1 . 0}$ \\
$-S$ & - & - & - & $\mathbf{1 . 0}$ & 0.7 & - & $\mathbf{1 . 0}$ & $\mathbf{1 . 0}$ & - & $\mathbf{1 . 0}$ & $\mathbf{1 . 0}$ & $\mathbf{1 . 0}$ & $\mathbf{1 . 0}$ & $\mathbf{1 . 0}$ & - \\
$622482-G$ & - & - & - & - & -0.5 & - & - & - & - & - & - & - & - & - & - \\
$-S$ & -0.8 & - & - & - & 0.7 & - & - & - & - & - & - & - & - & - & - \\
\hline
\end{tabular}

Table A4. Same as Table A1 but for the $\mathrm{HCl}$ line parameters.

\begin{tabular}{|c|c|c|c|c|c|c|c|c|c|c|c|c|c|c|c|}
\hline Parameter & \multicolumn{3}{|c|}{ LOS wind } & \multicolumn{3}{|c|}{$\mathrm{O}_{3}$} & \multicolumn{3}{|c|}{ Temperature } & \multicolumn{3}{|c|}{$\mathrm{H}_{2} \mathrm{O}$} & \multicolumn{3}{|c|}{$\mathrm{HCl}$} \\
\hline $624964-S$ & -0.6 & - & - & - & - & - & -0.6 & 0.5 & - & - & - & - & - & - & - \\
\hline $624977-G$ & - & - & - & - & - & - & 0.6 & - & - & - & - & - & - & - & - \\
\hline$-S$ & - & - & - & - & - & - & -1.0 & 0.5 & - & - & - & - & - & - & - \\
\hline $625901-F$ & - & 0.6 & 0.6 & - & - & - & - & - & - & - & - & - & - & - & - \\
\hline$-G$ & 0.9 & - & - & -0.7 & -0.7 & -0.6 & -0.6 & -0.9 & - & - & -0.6 & -0.6 & - & - & - \\
\hline$-S$ & -1.0 & - & - & - & - & - & 1.0 & - & 0.5 & - & - & - & 0.7 & 0.5 & 0.6 \\
\hline $625918-F$ & - & 1.0 & 1.0 & - & - & - & - & - & 0.5 & - & - & - & - & - & - \\
\hline$-G$ & - & - & - & -1.0 & -1.0 & -1.0 & - & -1.0 & 1.0 & -1.0 & -1.0 & -1.0 & - & -0.5 & - \\
\hline$-S$ & 1.0 & - & - & - & - & - & 0.6 & -1.0 & 0.6 & 0.7 & - & - & 1.0 & 1.0 & 1.0 \\
\hline $625931-G$ & -0.6 & - & - & - & - & - & - & -0.5 & - & - & - & - & - & - & - \\
\hline$-S$ & 1.0 & - & - & - & - & - & - & - & -0.7 & - & - & - & - & - & - \\
\hline
\end{tabular}


Author contributions. DM and PB designed the mission concept and the study. PB performed the simulations and wrote the manuscript using valuable information from all co-authors. KP and MS provided atmospheric model data. DM is the mission PI. DM, $\mathrm{PE}, \mathrm{JM}$ and KP wrote the mission proposal.

Competing interests. The authors declare that they have no conflict of interest

Acknowledgements. Omnisys Instruments (Sweden) designed the instrument and has provided hardware information used in this study. WACCM data were provided by Yvan Orsolini (NILU, Norway), Varavut Limpasuvan (Coastal Carolina University, USA) and Naohiro Manago (Chiba University, Japan). We also would like to thank the two anonymous reviewers for having provided valuable comments on the study and the mission.

Edited by: Gerd Baumgarten

Reviewed by: two anonymous referees

\section{References}

Baldwin, M., Thompson, D. W. J., Shuckburgh, E. F., Norton, W. A., and Gillett, N. P.: Weather from the Stratosphere?, Science, 301, 317-318, 2003.

Baldwin, M. P., Gillett, N. P., Forster, P., Gerber, E. P., Hegglin, M. I., Karpechko, A. Y., Kim, J., Kushner, P. J., Morgenstern, O. H., and Reichler, T.: Effects of the Stratosphere on the Troposphere, chap. 10, WMO/ICSU/IOC World Climate Research Programme, 2010.

Baron, P., Urban, J., Sagawa, H., Möller, J., Murtagh, D. P., Mendrok, J., Dupuy, E., Sato, T. O., Ochiai, S., Suzuki, K., Manabe, T., Nishibori, T., Kikuchi, K., Sato, R., Takayanagi, M., Murayama, Y., Shiotani, M., and Kasai, Y.: The Level 2 research product algorithms for the Superconducting Submillimeter-Wave Limb-Emission Sounder (SMILES), Atmos. Meas. Tech., 4, 2105-2124, https://doi.org/10.5194/amt-4-2105-2011, 2011.

Baron, P., Murtagh, D. P., Urban, J., Sagawa, H., Eriksson, P., and Ochiai, S.: Definition of an uncooled Sub-Millimeter/THz Limb sounder for measuring middle atmospheric winds, ESA Living Planet Symposium, 9-13 September, Edinburgh (UK), 1-8, 2013a.

Baron, P., Murtagh, D. P., Urban, J., Sagawa, H., Ochiai, S., Kasai, Y., Kikuchi, K., Khosrawi, F., Körnich, H., Mizobuchi, S., Sagi, K., and Yasui, M.: Observation of horizontal winds in the middle-atmosphere between $30^{\circ} \mathrm{S}$ and $55^{\circ} \mathrm{N}$ during the northern winter 2009-2010, Atmos. Chem. Phys., 13, 6049-6064, https://doi.org/10.5194/acp-13-6049-2013, 2013b.

Baumgarten, G.: Doppler Rayleigh/Mie/Raman lidar for wind and temperature measurements in the middle atmosphere up to $80 \mathrm{~km}$, Atmos. Meas. Tech., 3, 1509-1518, https://doi.org/10.5194/amt-3-1509-2010, 2010.

Blanc, E., Ceranna, L., Hauchecorne, A., Charlton-Perez, A., Marchetti, E., Evers, L. G., Kvaerna, T., Lastovicka, J., Eliasson, L., Crosby, N. B., Blanc-Benon, P., Le Pichon, A., Brachet, N., Pilger, C., Keckhut, P., Assink, J. D., Smets, P. S. M., Lee, C. F.,
Kero, J., Sindelarova, T., Kämpfer, N., Rüfenacht, R., Farges, T., Millet, C., Näsholm, S. P., Gibbons, S. J., Espy, P. J., Hibbins, R. E., Heinrich, P., Ripepe, M., Khaykin, S., Mze, N., and Chum, J.: Toward an Improved Representation of Middle Atmospheric Dynamics Thanks to the ARISE Project, Surv. Geophys., 39, 171-225, https://doi.org/10.1007/s10712-017-9444-0, 2018.

Christensen, O. M., Eriksson, P., Urban, J., Murtagh, D., Hultgren, K., and Gumbel, J.: Tomographic retrieval of water vapour and temperature around polar mesospheric clouds using Odin-SMR, Atmos. Meas. Tech., 8, 1981-1999, https://doi.org/10.5194/amt8-1981-2015, 2015.

Duruisseau, F., Huret, N., Andral, A., and Camy-Peyret, C.: Assessment of the ERA-Interim Winds Using High-Altitude Stratospheric Balloons, J. Atmos. Sci., 74, 2065-2080, https://doi.org/10.1175/JAS-D-16-0137.1, 2017.

Eriksson, P., Rydberg, B., Sagawa, H., Johnston, M. S., and Kasai, Y.: Overview and sample applications of SMILES and Odin-SMR retrievals of upper tropospheric humidity and cloud ice mass, Atmos. Chem. Phys., 14, 12613-12629, https://doi.org/10.5194/acp-14-12613-2014, 2014.

Gerber, E. P., Butler, A., Calvo, N., Charlton-Perez, A., Giorgetta, M., Manzini, E., Perlwitz, J., Polvani, L. M., Sassi, F., Scaife, A. A., Shaw, T. A., Son, S.-W., and Watanabe, S.: Assessing and Understanding the Impact of Stratospheric Dynamics and Variability on the Earth System, B. Am. Meteorol. Soc., 93, 845-859, https://doi.org/10.1175/bams-d-11-00145.1, 2012.

Hegglin, M. I. and Tegtmeier, S.: The SPARC Data Initiative: Assessment of stratospheric trace gas and aerosol climatologies from satellite limb sounders., SPARC Report No. 8, WCRP-5/2017, availale at: www.sparc-climate.org/publications/ sparc-reports/ (last access: 26 July 2018), 2017.

Hoppel, K. W., Baker, N. L., Coy, L., Eckermann, S. D., McCormack, J. P., Nedoluha, G. E., and Siskind, D. E.: Assimilation of stratospheric and mesospheric temperatures from MLS and SABER into a global NWP model, Atmos. Chem. Phys., 8, 6103-6116, https://doi.org/10.5194/acp-8-6103-2008, 2008.

Ishii, S., Baron, P., Aoki, M., Mizutani, K., Yasui, M., Ochiai, S., Sato, A., Satoh, Y., Kubota, T., Sakaizawa, D., Oki, R., Okamoto, K., Ishibashi, T., Tanaka, T. Y., Sekiyama, T. T., Maki, T., Yamashita, K., Nishizawa, T., Satoh, M., and Iwasaki, T.: Feasibility Study for Future Space-Borne Coherent Doppler Wind Lidar, Part 1: Instrumental Overview for Global Wind Profile Observation, J. Meteorol. Soc. Jpn., 95, 301-317, https://doi.org/10.2151/jmsj.2017-017, 2017.

Jarnot, R. F., Perun, V. S., and Schwartz, M. J.: Radiometric and spectral performance and calibration of the $\mathrm{GHz}$ bands of EOS MLS, IEEE T. Geosci. Remote, 44, 1131-1143, 2006.

Kasai, Y., Sagawa, H., Kreyling, D., Dupuy, E., Baron, P., Mendrok, J., Suzuki, K., Sato, T. O., Nishibori, T., Mizobuchi, S., Kikuchi, K., Manabe, T., Ozeki, H., Sugita, T., Fujiwara, M., Irimajiri, Y., Walker, K. A., Bernath, P. F., Boone, C., Stiller, G., von Clarmann, T., Orphal, J., Urban, J., Murtagh, D., Llewellyn, E. J., Degenstein, D., Bourassa, A. E., Lloyd, N. D., Froidevaux, L., Birk, M., Wagner, G., Schreier, F., Xu, J., Vogt, P., Trautmann, T., and Yasui, M.: Validation of stratospheric and mesospheric ozone observed by SMILES from International Space Station, Atmos. Meas. Tech., 6, 2311-2338, https://doi.org/10.5194/amt6-2311-2013, 2013. 
Kawatani, Y., Hamilton, K., Miyazaki, K., Fujiwara, M., and Anstey, J. A.: Representation of the tropical stratospheric zonal wind in global atmospheric reanalyses, Atmos. Chem. Phys., 16, 6681-6699, https://doi.org/10.5194/acp-16-6681-2016, 2016.

Khosravi, M., Baron, P., Urban, J., Froidevaux, L., Jonsson, A. I., Kasai, Y., Kuribayashi, K., Mitsuda, C., Murtagh, D. P., Sagawa, H., Santee, M. L., Sato, T. O., Shiotani, M., Suzuki, M., von Clarmann, T., Walker, K. A., and Wang, S.: Diurnal variation of stratospheric and lower mesospheric $\mathrm{HOCl}, \mathrm{ClO}$ and $\mathrm{HO}_{2}$ at the equator: comparison of 1-D model calculations with measurements by satellite instruments, Atmos. Chem. Phys., 13, 75877606, https://doi.org/10.5194/acp-13-7587-2013, 2013.

Kikuchi, K., Nishibori, T., Ochiai, S., Ozeki, H., Irimajiri, Y., Kasai, Y., Koike, M., Manabe, T., Mizukoshi, K., Murayama, Y., Nagahama, T., Sano, T., Sato, R., Seta, M., Takahashi, C., Takayanagi, M., Masuko, H., Inatani, J., Suzuki, M., and Shiotani, M.: Overview and early results of the Superconducting Submillimeter-Wave LimbEmission Sounder (SMILES), J. Geophys. Res., 115, D23306, https://doi.org/10.1029/2010JD014379, 2010.

Kursinski, E. R., Hajj, G. A., Schofield, J. T., Linfield, R. P., and Hardy, K. R.: Observing Earth's atmosphere with radio occultation measurements using the Global Positioning System, J. Geophys. Res.-Atmos., 102, 23429-23465, https://doi.org/10.1029/97JD01569, 1997.

Kuttippurath, J. and Nikulin, G.: A comparative study of the major sudden stratospheric warmings in the Arctic winters 2003/2004-2009/2010, Atmos. Chem. Phys., 12, 8115-8129, https://doi.org/10.5194/acp-12-8115-2012, 2012.

Le Pichon, A., Assink, J. D., Heinrich, P., Blanc, E., CharltonPerez, A., Lee, C. F., Keckhut, P., Hauchecorne, A., Rüfenacht, R., Kämpfer, N., Drob, D. P., Smets, P. S. M., Evers, L. G., Ceranna, L., Pilger, C., Ross, O., and Claud, C.: Comparison of co-located independent ground-based middle atmospheric wind and temperature measurements with numerical weather prediction models, J. Geophys. Res.-Atmos., 120, 8318-8331, https://doi.org/10.1002/2015JD023273, 2015.

Limpasuvan, V., Richter, J. H., Orsolini, Y. J., Stordal, F., and Kvissel, O.-K.: The roles of planetary and gravity waves during a major stratospheric sudden warming as characterized in WACCM, J. Atmos. Sol.-Terr. Phy., 78-79, 84-98, https://doi.org/10.1016/j.jastp.2011.03.004, 2012.

Lindberg, R.: Call for Proposals for a Scientific Swedish Satellite based on the InnoSat Platform, available at: http://www. rymdstyrelsen.se/en/Home/Home/ (last access: 27 July 2018), 2016.

Livesey, N. J. and Santee, M. L.: Prospects for future spaceborne measurements of interest to the SPARC DA Community and how to improve those prospects, in: S-RIP 2017 and 13th SPARCDA Workshop, availabel at: https://events.oma.be/indico/event/ 18/material/slides/16.pdf (last access: 27 July 2018), 2017.

Livesey, N. J., Snyder, W. V., Read, W. G., and Wagner, P. A.: Retrieval algorithms for the EOS Microwave limb sounder (MLS), IEEE T. Geosci. Remote, 44, 1144-1155, https://doi.org/10.1109/TGRS.2006.872327, 2006.

Livesey, N. J., Read, W. G., Froidevaux, L., Lambert, A., Manney, G. L., Pumphrey, H. C., Santee, M. L., Schwartz, M. J., Wang, S., Cofield, R. E., Cuddy, D. T., Fuller, R. A., Jarnot, R. F., Jiang, J. H., Knosp, B. W., Stek, P. C., Wagner, P. A., and Wu., D. L.: EOS MLS Level 2 Version 3.3 Quality Document, Tech. rep., Jet Propulsion Laboratory, California Institute of Technology, Pasadena, California, 91109-8099, available at: http://mls.jpl.nasa.gov/data/datadocs.php (last access: 27 July 2018), 2011.

Marsh, D. R., Mills, M. J., Kinnison, D. E., Lamarque, J.-F., Calvo, N., and Polvani, L. M.: Climate Change from 1850 to 2005 Simulated in CESM1(WACCM), J. Climate, 26, 7372-7391, https://doi.org/10.1175/JCLI-D-12-00558.1, 2013.

Millán, L., Wang, S., Livesey, N., Kinnison, D., Sagawa, H., and Kasai, Y.: Stratospheric and mesospheric HO2 observations from the Aura Microwave Limb Sounder, Atmos. Chem. Phys., 15, 2889-2902, https://doi.org/10.5194/acp-15-2889-2015, 2015.

Murtagh, D.: SIW-Stratospheric Inferred Winds. Proposal in response to a Scientific Swedish Satellite based on the InnoSat Platform, Tech. rep., 2016.

Murtagh, D., Frisk, U., Merino, F., Ridal, M., Jonsson, A., Stegman, J., Witt, G., Eriksson, P., Jimenez, C., Mégie, G., de la Noë, J., Ricaud, P., Baron, P., Pardo, J., Hauchcorne, A., Llewellyn, E., Degenstein, D., Gattinger, R., Lloyd, N., Evans, W., McDade, I., Haley, C., Sioris, C., von Savigny, C., Solheim, B., McConnell, J., Strong, K., Richardson, E., Leppelmeier, G., Kyrola, E., Auvinen, H., and Oikarinen, L.: An overview of the Odin atmospheric mission, Can. J. Phys., 80, 309-319, https://doi.org/10.1139/P01157, 2002.

Newman, P. A., Coy, L., Pawson, S., and Lait, L. R.: The anomalous change in the QBO in 2015-2016, Geophys. Res. Lett., 43, 8791-8797, https://doi.org/10.1002/2016GL070373, 2016.

Ochiai, S., Kikuchi, K., Nishibori, T., Manabe, T., Ozeki, H., Mizobuchi, S., and Irimajiri, Y.: Receiver Performance of the Superconducting Submillimeter-Wave Limb-Emission Sounder (SMILES) on the International Space Station, IEEE T. Geosci. Remote, 51, 3791-3802, https://doi.org/10.1109/TGRS.2012.2227758, 2013.

Ochiai, S., Baron, P., Nishibori, T., Irimajiri, Y., Uzawa, Y., Manabe, T., Maezawa, H., Mizuno, A., Nagahama, T., Sagawa, H., Suzuki, M., and Shiotani, M.: SMILES-2 mission for temperature, wind, and composition in the whole atmosphere, SOLA, 13A, 13-18, https://doi.org/10.2151/sola.13A-003, 2017.

Olberg, M., Frisk, U., Lecacheux, A., Olofsson, A., Baron, P., Bergman, P., Florin, G., Hjalmarsson, A., Larsson, B., Murtagh, D., Olofsson, G., Pagani, L., Sandqvist, A., Teyssier, D., Torchinsky, S. A., and Volk, K.: The Odin satellite - II. Radiometer data processing and calibration, A\&A, 402, L35-L38, https://doi.org/10.1051/0004-6361:20030336, 2003.

Orsolini, Y. J., Limpasuvan, V., Pérot, K., Espy, P., Hibbins, R., Lossow, S., Larsson, K. R., and Murtagh, D.: Modelling the descent of nitric oxide during the elevated stratopause event of January 2013, J. Atmos. Sol.-Terr. Phy., 155, 50-61, https://doi.org/10.1016/j.jastp.2017.01.006, 2017.

Ortland, D. A., Skinner, W. R., Hays, P. B., Burrage, M. D., Lieberman, R. S., Marshall, A. R., and Gell, D. A.: Measurements of stratospheric winds by the High Resolution Doppler Imager, J. Geophys. Res., 101, 10351-10363, 1996.

Pérot, K., Urban, J., and Murtagh, D. P.: Unusually strong nitric oxide descent in the Arctic middle atmosphere in early 2013 as observed by Odin/SMR, Atmos. Chem. Phys., 14, 8009-8015, https://doi.org/10.5194/acp-14-8009-2014, 2014. 
Pickett, H. M., Poynter, R. L., Cohen, E. A., Delitsky, M. L., Pearson, J. C., and Müller, H. S. P.: Submillimeter, millimeter and microwave spectral line catalog., J. Quant. Spectrosc. Ra., 60, 883890, https://doi.org/10.1016/S0022-4073(98)00091-0, 1998.

Pumphrey, H. C., Read, W. G., Livesey, N. J., and Yang, K.: Observations of volcanic $\mathrm{SO}_{2}$ from MLS on Aura, Atmos. Meas. Tech., 8, 195-209, https://doi.org/10.5194/amt-8-195-2015, 2015.

Rahnama, P., Gault, W. A., McDade, I. C., and Shepherd, G. G.: Scientific Assessment of the SWIFT Instrument Design, J. Atmos. Ocean. Tech., 30, 2081-2094, https://doi.org/10.1175/JTECHD-12-00230.1, 2013.

Randall, C. E., Harvey, V. L., Singleton, C. S., Bailey, S. M., Bernath, P. F., Codrescu, M., Nakajima, H., and Russell, J. M.: Energetic particle precipitation effects on the Southern Hemisphere stratosphere in 1992?2005, J. Geophys. Res.-Atmos., 112, D08308, https://doi.org/10.1029/2006JD007696, 2007.

Rothman, L., Gordon, I., Barbe, A., Benner, D., Bernath, P., Birk, M., Boudon, V., Brown, L., Campargue, A., Champion, J.-P., Chance, K., Coudert, L., Dana, V., Devi, V., Fally, S., Flaud, J.M., Gamache, R., Goldman, A., Jacquemart, D., Kleiner, I., Lacome, N., Lafferty, W., Mandin, J.-Y., Massie, S., Mikhailenko, S., Miller, C., Moazzen-Ahmadi, N., Naumenko, O., Nikitin, A., Orphal, J., Perevalov, V., Perrin, A., Predoi-Cross, A., Rinsland, C., Rotger, M., Smith, M., Sung, K., Tashkun, S., Tennyson, J., Toth, R., Vandaele, A., and Auwera, J. V.: The HITRAN 2008 molecular spectroscopic database, J. Quant. Spectrosc. Ra., 110, 533-572, https://doi.org/10.1016/j.jqsrt.2009.02.013, 2009.

Rüfenacht, R., Murk, A., Kämpfer, N., Eriksson, P., and Buehler, S. A.: Middle-atmospheric zonal and meridional wind profiles from polar, tropical and midlatitudes with the ground-based microwave Doppler wind radiometer WIRA, Atmos. Meas. Tech., 7, 4491-4505, https://doi.org/10.5194/amt-7-4491-2014, 2014.

Rüfenacht, R., Baumgarten, G., Hildebrand, J., Schranz, F., Matthias, V., Stober, G., Lübken, F.-J., and Kämpfer, N.: Intercomparison of middle-atmospheric wind in observations and models, Atmos. Meas. Tech., 11, 1971-1987, https://doi.org/10.5194/amt-11-1971-2018, 2018.

Sagawa, H., Sato, T. O., Baron, P., Dupuy, E., Livesey, N., Urban, J., von Clarmann, T., de Lange, A., Wetzel, G., Connor, B. J., Kagawa, A., Murtagh, D., and Kasai, Y.: Comparison of SMILES $\mathrm{ClO}$ profiles with satellite, balloon-borne and ground-based measurements, Atmos. Meas. Tech., 6, 33253347, https://doi.org/10.5194/amt-6-3325-2013, 2013.

Sakazaki, T., Fujiwara, M., and Shiotani, M.: Representation of solar tides in the stratosphere and lower mesosphere in state-of-the-art reanalyses and in satellite observations, Atmos. Chem. Phys., 18, 1437-1456, https://doi.org/10.5194/acp-181437-2018, 2018.
Shepherd, G. G.: Development of wind measurement systems for future space missions, Acta Astronaut., 115, 206-217, https://doi.org/10.1016/j.actaastro.2015.05.015, 2015.

Stoffelen, A., Pailleux, J., Källén, E., Vaughan, J., Isaksen, L., Flamant, P., Wergen, W., Andersson, E., Schyberg, H., Culoma, A., Meynart, R., Endemann, M., and Ingmann, P.: The Atmospheric Dynamics Mission For Global Wind Field Measurement, B. Am. Meteorol. Soc., 86, 73-87, 2005.

Urban, J., Baron, P., Lautié, N., Schneider, N., Dassas, K., Ricaud, P., and De La Noë, J.: MOLIERE (v5): a versatile forward- and inversion model for the millimeter and submillimeter wavelength range, J. Quant. Spectrosc. Ra., 83, 529554, https://doi.org/10.1016/S0022-4073(03)00104-3, 2004.

Urban, J., Lautié, N., Le Flochmoën, E., Jiménez, C., Eriksson, P., de La Noë, J., Dupuy, E., Ekström, M., El Amraoui, L., Frisk, U., Murtagh, D., Olberg, M., and Ricaud, P.: Odin/SMR limb observations of stratospheric trace gases: Level 2 processing of $\mathrm{ClO}$, $\mathrm{N}_{2} \mathrm{O}, \mathrm{HNO}_{3}$, and $\mathrm{O}_{3}$, J. Geophys. Res.-Atmos., 110, D14307, https://doi.org/10.1029/2004JD005741, 2005.

Waters, J. W., Froidevaux, L., Read, W. G., Manney, G. L., Elson, L. S., Flower, D. A., Jarnot, R. F., and Harwood, R. S.: Stratospheric $\mathrm{ClO}$ and ozone from the Microwave Limb Sounder on the Upper Atmosphere Research Satellite, Nature, 362, 597-602, https://doi.org/10.1038/362597a0, 1993.

Waters, J. W., Froidevaux, L., Harwood, R. S., Jarnot, R. F., Pickett, H. M., Read, W. G., Siegel, P. H., Cofield, R. E., Filipiak, M. J., Flower, D. A., Holden, J. R., Lau, G. K., Livesey, N. J., Manney, G. L., Pumphrey, H. C., Santee, M. L., Wu, D. L., Cuddy, D. T., Lay, R. R., Loo, M. S., Perun, V. S., Schwartz, M. J., Stek, P. C., Thurstans, R. P., Boyles, M. A., Chandra, K. M., Chavez, M. C., Chen, G.-S., Chudasama, B. V., Dodge, R., Fuller, R. A., Girard, M. A., Jiang, J. H., Jiang, Y., Knosp, B. W., LaBelle, R. C., Lam, J. C., Lee, K. A., Miller, D., Oswald, J. E., Patel, N. C., Pukala, D. M., Quintero, O., Scaff, D. M., Snyder, W. V., Tope, M. C., Wagner, P. A., and Walch, M. J.: The Earth observing system microwave limb sounder (EOS MLS) on the aura Satellite, IEEE T. Geosci. Remote, 44, 1075-1092, https://doi.org/10.1109/TGRS.2006.873771, 2006.

Wu, D. L., Schwartz, M. J., Waters, J. W., Limpasuvan, V., Wu, Q. A., and Killeen, T. L.: Mesospheric doppler wind measurements from Aura Microwave Limb Sounder (MLS), Adv. Space Res., 42, 1246-1252, 2008.

Wu, D. L., Yee, J.-H., Schlecht, E., Mehdi, I., Siles, J., and Drouin, B. J.: THz limb sounder (TLS) for lower thermospheric wind, oxygen density, and temperature, J. Geophys. Res.-Space, 121, 7301-7315, https://doi.org/10.1002/2015JA022314, 2016. 